\title{
BALANCE DE LA DESIGUALDAD Y El GASTO PÚBLICO EN ESPAÑA. ESPACIO ABIERTo De LUCHA Social
}

\begin{abstract}
Albert Ferrer Sánchez ${ }^{1}$
Resumen: Este artículo analiza la evolución de la pobreza y la desigualdad social en España (2007-2016). Indaga sobre su incremento de nivel actual y ofrece datos sobre el gasto público asociado. Por último, rastrea algunas de las consecuencias sociales que implica la persistencia de estos fenómenos sociales, su reflejo en la opinión pública española y su implicación en alguna de las movilizaciones sociales actuales, como es el caso de la que están protagonizando los jubilados.
\end{abstract}

Palabras clave: Desigualdad; pobreza; gasto social; conflicto social; conflicto político; pensiones

Resum: Aquest article analitza l'evolució de la pobresa i la desigualtat social a Espanya (2007-2016). Indaga sobre l'increment actual del nivell d'aquestes i ofereix dades sobre la despesa pública associada. Per últim, rastreja algunes de les conseqüències socials que implica la persistència d'aquests fenòmens socials, el seu reflex en l'opinió pública espanyola i la seva implicació en alguna de les mobilitzacions socials actuals, com és el cas de la que estan protagonitzant els jubilats.

\footnotetext{
${ }^{1}$ Licenciado en Ciencias Políticas y de la Administración (Universidad de Barcelona), titulado en el Máster Oficial de Ciudadanía y Derechos Humanos -ética y política(Universidad de Barcelona) y estudiante de doctorado en el programa Ciudadanía y Derechos Humanos de la Universidad de Barcelona. Correo electrónico: Albert.ferrer@yandex.com
} 
Paraules clau: Desigualtat; pobresa; despesa social; conflicte social; conflicte polític; pensions

Abstract: This article analyses the evolution of poverty and social inequality in Spain (2007-2016). It looks into their current increase and provides some data about the associated social expenditure. Finally, it explores some of the social consequences of the persistence of both social phenomena, the way that these are reflected in the Spanish public opinion, and their involvement in some of the present social mobilisations, such as those of the Spanish pensioners.

Keywords: Inequality; poverty; social expenditure; social conflict; political conflict; pensions

\section{Introducción}

En los últimos años, le economía española ha registrado tasas de crecimiento positivas, aunque modestas en relación a las registradas en los años anteriores al estallido de la crisis económica (2008-2014).

Tabla 1. Evolución del Producto Interior Bruto de España (2005-2016) ${ }^{2}$

\begin{tabular}{|l|l|l|l|l|l|l|l|l|l|l|l|}
\cline { 2 - 10 } \multicolumn{1}{c|}{} & $\mathbf{2 0 0 6}$ & $\mathbf{2 0 0 7}$ & $\mathbf{2 0 0 8}$ & $\mathbf{2 0 0 9}$ & $\mathbf{2 0 1 0}$ & $\mathbf{2 0 1 1}$ & $\mathbf{2 0 1 2}$ & $\mathbf{2 0 1 3}$ & $\mathbf{2 0 1 4}$ & $\mathbf{2 0 1 5}$ & $\mathbf{2 0 1 6}$ \\
\hline $\begin{array}{l}\text { Tasa variación } \\
\text { interanual } \\
\begin{array}{l}\text { PIB. Precios } \\
\text { corrientes (\%) }\end{array}\end{array}$ & 8,32 & 7,23 & 3,28 & $-3,33$ & 0,17 & $-0,97$ & $-2,86$ & $-1,36$ & 1,18 & 4,06 & 3,57 \\
\hline $\begin{array}{l}\text { Tasa variación } \\
\text { interanual } \\
\begin{array}{l}\text { PIB. Precios } \\
\text { constantes(\%) }\end{array}\end{array}$ & 4,17 & 3,77 & 1,12 & $-3,57$ & 0,01 & $-1,00$ & $-2,93$ & $-1,71$ & 1,38 & 3,43 & 3,27 \\
\hline
\end{tabular}

${ }^{2}$ Tabla de elaboración propia a partir de datos extraídos de los informes del INE.

B ANUARI DEL CONFLICTE SOCIAL 2017

DOI. 10.1344/ACS2018.7.6 
Partiendo de la constatación anterior, el Gobierno de España y diversos organismos nacionales e internacionales han anunciado el fin de la crisis económica y han establecido pronósticos económicos positivos para los próximos años. El Banco Central Europeo (BCE), por ejemplo, ha revisado la previsión de crecimiento de la economía española situándola un 2,4\% para el presente año y en un 1,9\% y 1,7\% los dos próximos años ${ }^{3}$. Por su parte, el Banco de España prevé un crecimiento del 2,7\% en 2018 y del 2,3\% y el 2,1\% en 2019 y 2020 respectivamente 4 . Por último, el Fondo Monetario Internacional (FMI) augura que la economía española crecerá un 2,8\% en el presente año $2018^{5}$.

No obstante, a pesar de los datos macroeconómicos anteriormente mencionados, la situación social en España no invita al optimismo. En primer lugar, en 2017, la tasa de paro media fue del 17,23\% $\%^{6}$ y superó en 9,63 puntos porcentuales la media de la Unión Europea. En 2016, el porcentaje de población situado bajo el umbral de la pobreza fue del 22,3\%, es decir, cinco puntos por encima del conjunto de la Unión Europea. Esta diferencia se vuelve más acusada para los menores de 18 años (8,7 puntos porcentuales). Sin embargo, el porcentaje de personas mayores de 65 años que viven por debajo del umbral de la pobreza en España es ligeramente inferior al del conjunto de la Unión Europea y la zona euro (Tabla 2).

3http://www.europapress.es/economia/macroeconomia-00338/noticia-bce-revisaalza-prevision-crecimiento-2018-advierte-amenaza-proteccionismo-

20180308152035.html

${ }^{4}$ https://www.diariocritico.com/banco-de-espana-mejora-las-previsioneseconomicas-2018

5 https://elpais.com/economia/2018/04/17/actualidad/1523923082_420998.html ${ }^{6}$ http://www.ine.es/ 
Tabla 2. Tasa de paro y porcentaje de población situada por debajo del umbral de la pobreza ${ }^{7}$

\begin{tabular}{|l|c|c|c|c|}
\cline { 2 - 5 } \multicolumn{1}{c|}{} & $\begin{array}{c}\text { Tasa de } \\
\text { paro } \\
\mathbf{( 2 0 1 7 )}\end{array}$ & $\begin{array}{c}\text { \% Bajo el } \\
\text { umbral de la } \\
\text { pobreza } \\
\mathbf{( 2 0 1 6 )}\end{array}$ & $\begin{array}{c}\text { \% Menores de 18 } \\
\text { bajo el umbral de } \\
\text { la pobreza (2016) }\end{array}$ & $\begin{array}{c}\text { \% Mayores de } \\
\text { 65 bajo el } \\
\text { umbral de la } \\
\text { pobreza (2016) }\end{array}$ \\
\hline $\begin{array}{l}\text { Unión Europea a 28 } \\
\text { (UE-28) }\end{array}$ & 7,6 & 17,3 & 21 & 14,6 \\
\hline Zona Euro & 9,1 & 17,4 & 20,8 & 14,2 \\
\hline España & 17,2 & 22,3 & 29,7 & 13 \\
\hline
\end{tabular}

En cuanto a la evolución de la desigualdad, la situación no es menos alarmante. Si medimos esta variable a través del índice de $\mathrm{Gini}^{8}$, comprobaremos que aumentó 2,3 puntos durante el periodo de crisis (2008-2014). Por otra parte, pese al crecimiento económico sostenido de la economía, la reducción de la desigualdad ha sido imperceptible en estos últimos años (apenas dos décimas). Así pues, podemos concluir que el nivel de desigualdad se ha estabilizado en niveles superiores a los registrados antes de la crisis (tabla 3).

Si comparamos los niveles de desigualdad de la sociedad española con los del conjunto de la Unión Europea (UE) y la eurozona, el resultado es realmente sorprendente. En 2016, la desigualdad en España superaba en 3,7 puntos el rango de desigualdad del conjunto de la UE y en 3,8 la desigualdad en la zona euro. Además de esta diferencia en términos absolutos, la desigualdad social en España ha seguido una evolución particular.

7 http://ec.europa.eu/eurostat/data/database

${ }_{8}^{8}$ Esta variable mide la desigualdad del ingreso a través de una escala del 0 al 100 siendo " 0 " una sociedad en la que todos los habitantes reciben el mismo ingreso. 
Entre los años 2008 y 2014, la desigualdad medida en términos de Gini no aumentó en el conjunto de la UE-279. Sin embargo, sí lo hizo ligeramente en la eurozona, aunque la diferencia fue irrisoria. En resumen, se ha producido una divergencia entre nuestro país y la estimación d conjunto de socios comunitarios en términos de desigualdad social.

Tabla 3. Índice de Gini 2008-2016 (España-UE) ${ }^{10}$

\begin{tabular}{|l|c|c|c|c|c|c|c|c|c|}
\cline { 2 - 10 } \multicolumn{1}{c|}{} & $\mathbf{2 0 0 8}$ & $\mathbf{2 0 0 9}$ & $\mathbf{2 0 1 0}$ & $\mathbf{2 0 1 1}$ & $\mathbf{2 0 1 2}$ & $\mathbf{2 0 1 3}$ & $\mathbf{2 0 1 4}$ & $\mathbf{2 0 1 5}$ & $\mathbf{2 0 1 6}$ \\
\hline Unión Europea a 28 (UE-28) & -- & -- & 30,5 & 30,8 & 30,5 & 30,5 & 31 & 31 & 30,8 \\
\hline Unión Europea a 27 (UE-27) & 31 & 30,6 & 30,5 & 30,8 & 30,5 & 30,5 & 31 & 31 & 30,8 \\
\hline Zona Euro & 30,5 & 30,3 & 30,3 & 30,6 & 30,5 & 30,7 & 31 & 30,8 & 30,7 \\
\hline España & 32,4 & 32,9 & 33,5 & 34 & 34,2 & 33,7 & 34,7 & 34,6 & 34,5 \\
\hline
\end{tabular}

Son tres los objetivos de este artículo: En primer lugar, se pretende averiguar el origen de estos incrementos de desigualdad y pobreza. En segundo lugar, se trata de descubrir por qué el gasto público no ha sido eficaz a la hora de mitigar la pobreza y la desigualdad social. Y, por último, analiza los posibles efectos políticos que puede producir la persistencia de estos fenómenos sociales.

\section{La desigualdad social y sus características en términos comparados}

Como se ya se ha mostrado, la desigualdad social registrada en España creció considerablemente durante la crisis y se ha estabilizado en niveles superiores a los del periodo anterior. En términos comparados,

\footnotetext{
${ }^{9}$ Unión Europea antes de la incorporación de Croacia. El bajo nivel demográfico de este país hace que el índice a penas presente variación tras su incorporación.

${ }^{10}$ Datos de Eurostat.
} 
España es el séptimo país más desigual de la Unión Europea (Gráfico 1). Además, entre los años 2014 y 2016, España ha superado al resto de países sur europeos (Portugal y Grecia) en términos de desigualdad social (gráfico 2).



Gráfico 1. Índice de Gini (Promedio 2007-2016) ${ }^{11}$

11 Todos los gráficos comprendidos entre el uno y el nueve han sido elaborados con datos de Eurostat. 


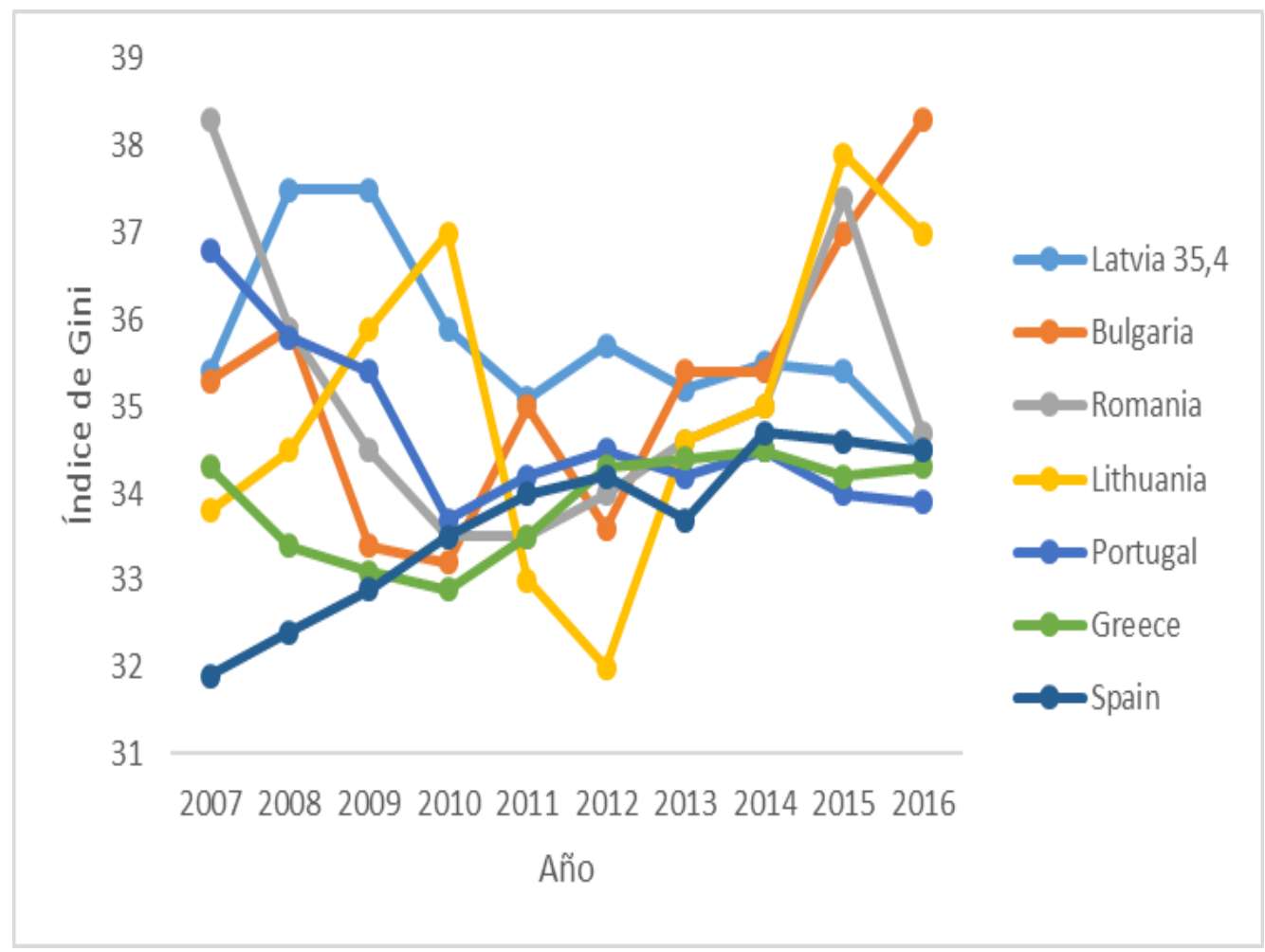

Gráfico 2. Evolución comparada del índice de Gini

Sin embargo, en términos de desarrollo económico relativo (PIB/Cápita), España no difiere excesivamente de sus socios comunitarios. De hecho, entre los años 2007 y 2016, el promedio de esta variable fue el 92,95\% del conjunto de la Unión Europea (UE-27). Así pues, España presenta un nivel de desarrollo intermedio y se sitúa muy lejos de las economías europeas menos desarrolladas (40,7 puntos por encima de Letonia, 42,4 por encima de Rumania y 47,9 por encima de Bulgaria). 


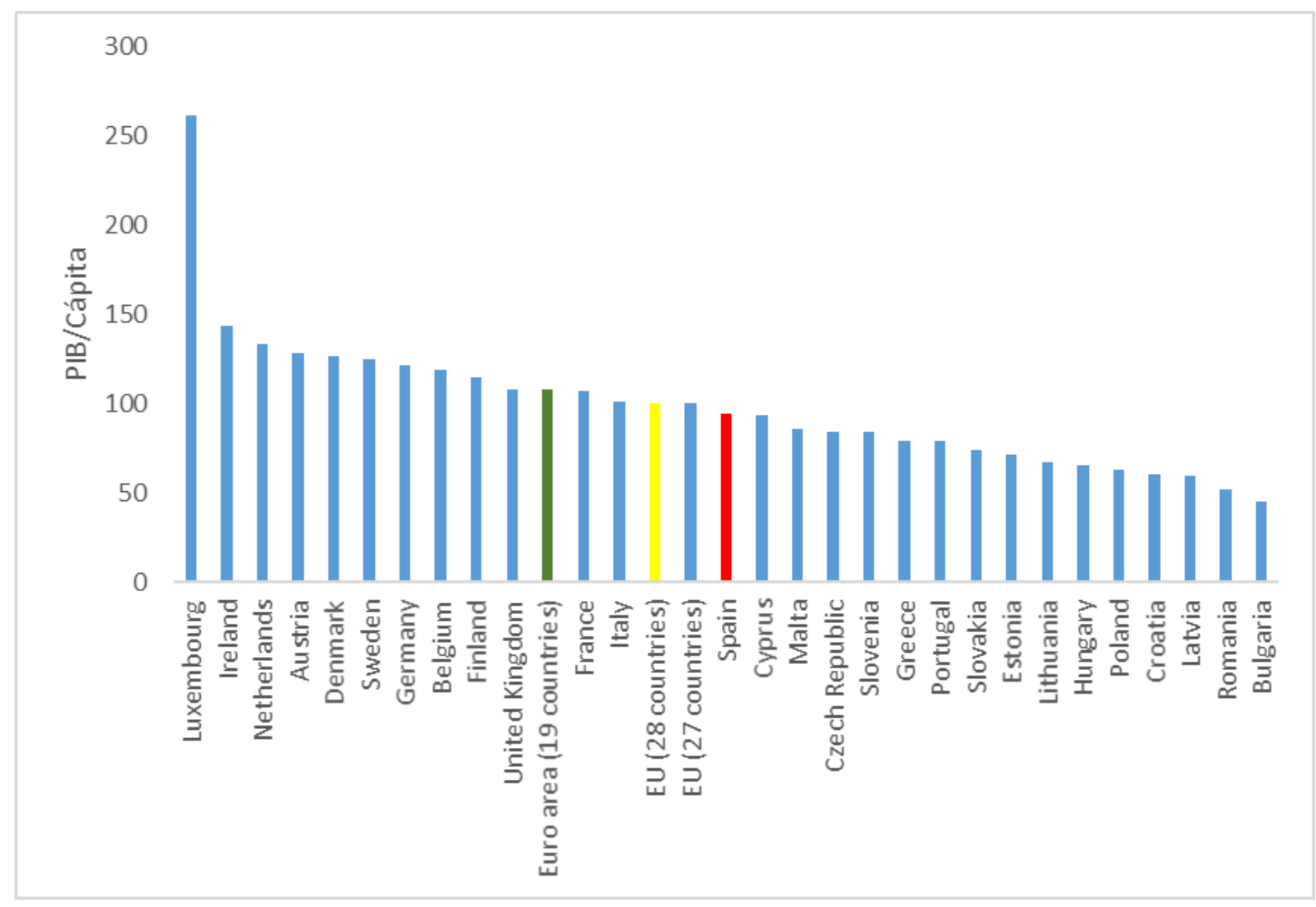

Gráfico 3. PIB/Cápita medio del periodo 2007-2016 (UE-28=100)

$\mathrm{Si}$ relacionamos estadísticamente las variables PIB/Cápita y desigualdad, obtenemos una correlación inversa, aunque muy débil (Gráfico 4). En cuanto a España, cabe destacar que registra un nivel de desigualdad muy superior al que le correspondería por su nivel de desarrollo. En otras palabras, España tiene un nivel de desigualdad impropio de su nivel de desarrollo y, a su vez, es el país más desarrollado entre los países más desiguales de la Unión.

A la vista de esta valoración, podríamos caer en la tentación de atribuir las enormes desigualdades sociales a un gasto social relativamente bajo, puesto que los estados suelen usarlo como herramienta para mitigar la

B ANUARI DEL CONFLICTE SOCIAL 2017 
divergencia social surgida del mundo del trabajo. Y, si comparamos el promedio del gasto social como porcentaje del PIB de España con el de los países de su entorno, esta interpretación es como mínimo plausible. Sin embargo, aunque en el caso español esta variable se sitúa 4,40 puntos porcentuales por debajo del conjunto de la eurozona y 3,71 puntos por debajo de la UE-27 (gráfico 5), también vemos que el gasto social en España es considerablemente mayor que el de los países de menor inversión social de la Unión -7,56 puntos porcentuales por encima de Lituania; 7,66 puntos por encima de Bulgaria; 8,58 puntos por encima de Estonia y 9,54 puntos por encima de Letonia-.

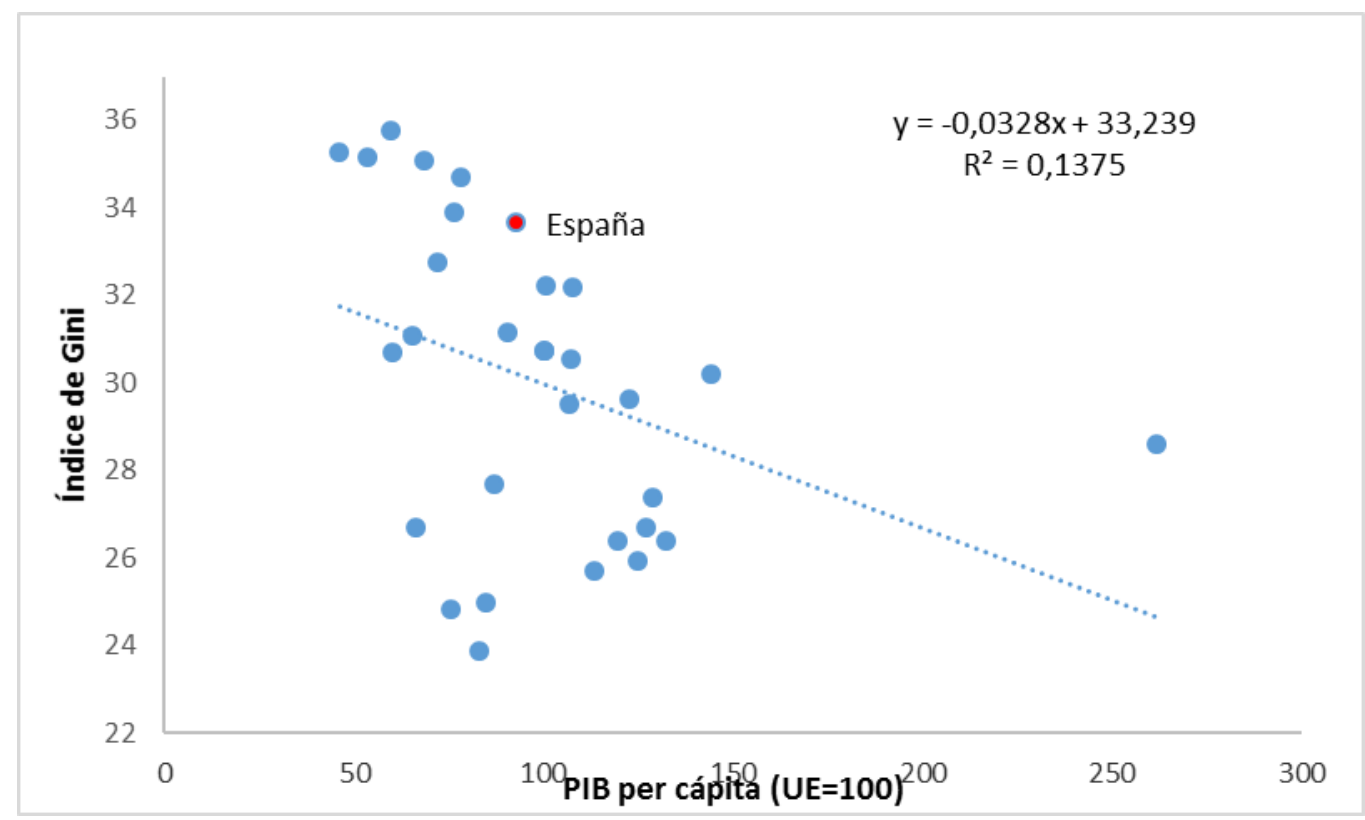

Gráfico 4. Correlación PIB per Cápita-Índice Gini (promedios 2007-2016) 


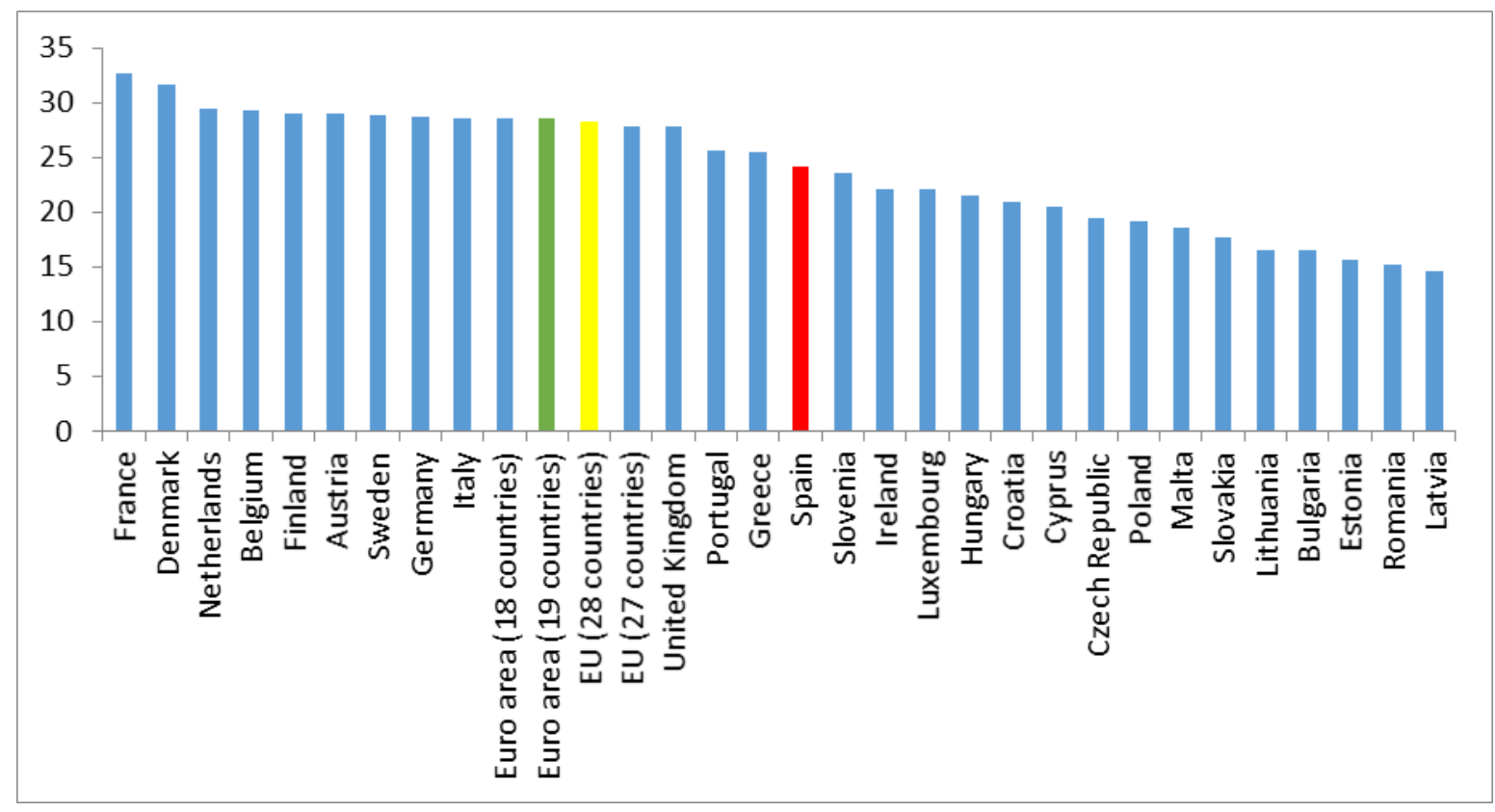

\section{Gráfico 5. \% Gasto social del PIB (promedio 20017-2015) ${ }^{12}$}

Si establecemos una correlación entre el gasto social como porcentaje del PIB (X) y el índice de Gini ${ }^{13}$ (gráfico 6), podemos dividir los países europeos en tres categorías: 1) Los países que presentan grandes niveles de desigualdad y un escaso gasto social -repúblicas bálticas y países de Europa del Este-; 2) Los países que efectúan un gran gasto social y tienen un nivel de desigualdad interna relativamente escaso países escandinavos- y 3) Los países que registran niveles de desigualdad considerables, pero su gasto social es notoriamente más alto que el de los países más desiguales de la Unión (España, Grecia y Portugal). En este último tipo de países, la elevada desigualdad social no proviene de la escasa cuantía del gasto social en términos absolutos,

\footnotetext{
12 En 2015, no está contabilizada Polonia. Tampoco había datos de 2016.

$13 \mathrm{El}$ gasto social de los países situados por encima de la línea de tendencia es poco eficiente reduciendo las desigualdades.
} 
si no de su ineficacia. Esta proposición puede verificarse observando el impacto de las transferencias públicas sobre el índice de Gini. Para ello, es necesario calcular la diferencia entre el índice de Gini antes (tabla 4) y después (tabla 3) de que el estado efectúe las transferencias públicas $^{14}$. Como puede comprobarse en la tabla 5 , las transferencias públicas efectuadas por las administraciones españolas redujeron la desigualdad solamente un promedio de 14,2 puntos en la escala de Gini entre los años 2008 y 2016. Mientras tanto, en el conjunto de la Unión Europea, las transferencias públicas redujeron la desigualdad en más de veinte puntos.

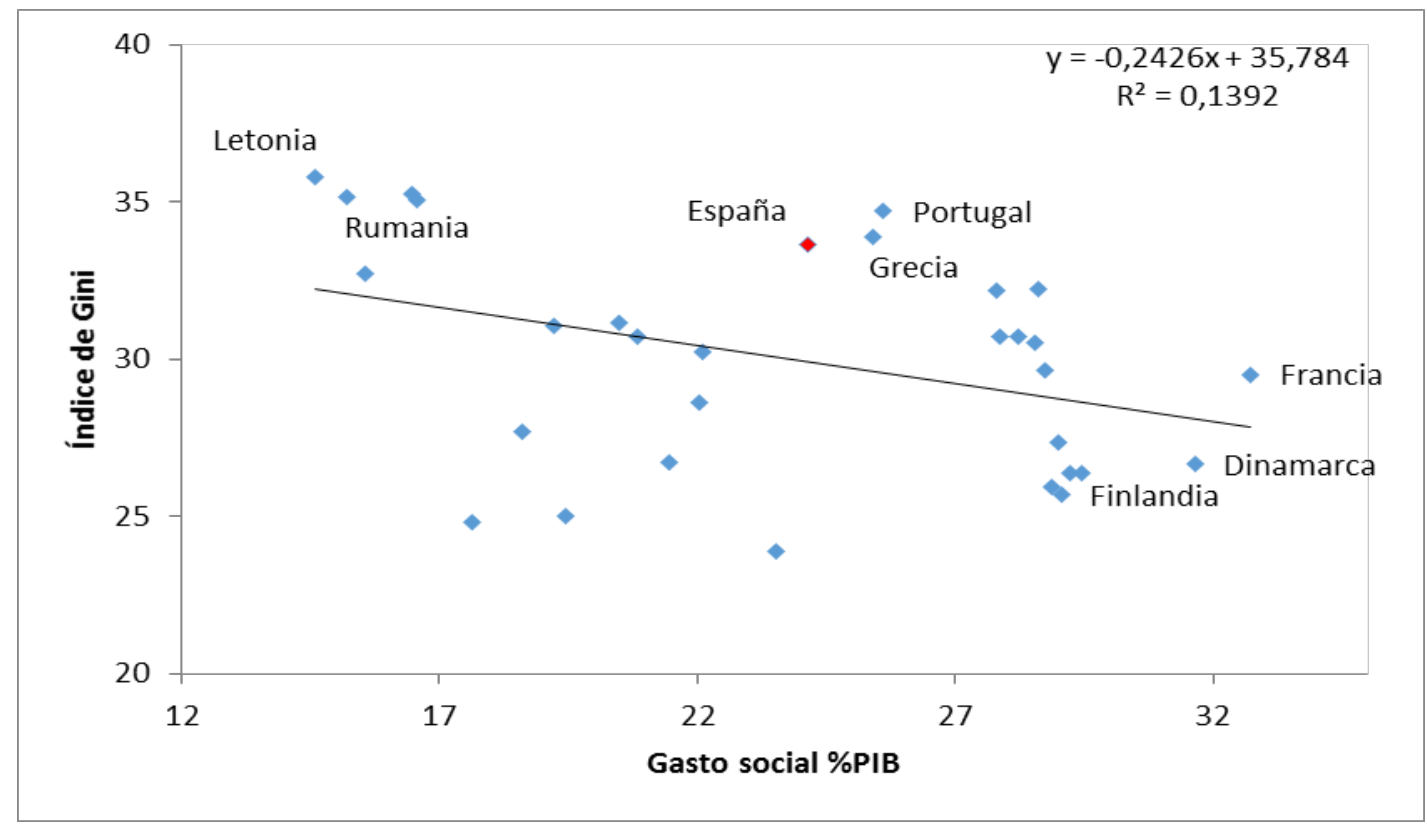

Gráfico 6. Correlación Gini - Gasto social \% PIB (promedio 2007-2015)

${ }^{14}$ Dentro de transferencias públicas, hay que computar todo prestación económica en términos monetarios.

๑

ANUARI DEL CONFLICTE SOCIAL 2017

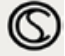

DOI. 10.1344/ACS2018.7.6 
Tabla 4. Índice de Gini antes de transferencias públicas ${ }^{15}$

\begin{tabular}{|l|c|c|c|c|c|c|c|c|c|}
\cline { 2 - 10 } \multicolumn{1}{c|}{} & $\mathbf{2 0 0 8}$ & $\mathbf{2 0 0 9}$ & $\mathbf{2 0 1 0}$ & $\mathbf{2 0 1 1}$ & $\mathbf{2 0 1 2}$ & $\mathbf{2 0 1 3}$ & $\mathbf{2 0 1 4}$ & $\mathbf{2 0 1 5}$ & $\mathbf{2 0 1 6}$ \\
\hline $\begin{array}{l}\text { Unión Europea (UE- } \\
\text { 28) }\end{array}$ & 49,6 & 49,6 & 50,1 & 50,7 & 50,9 & 51,4 & 51,9 & 51,8 & 51,6 \\
\hline $\begin{array}{l}\text { Unión Europea (UE- } \\
\text { 27) }\end{array}$ & 49,6 & 49,6 & 50,1 & 50,8 & 50,9 & 51,5 & 52 & 51,8 & 51,6 \\
\hline Eurozona & 49 & 48,8 & 49,6 & 50,4 & 50,4 & 51,3 & 51,9 & 51,6 & 51,6 \\
\hline España & 43,4 & 44,5 & 46,8 & 48,8 & 48,7 & 49,3 & 50,9 & 50,8 & 50,7 \\
\hline
\end{tabular}

Tabla 5. Diferencial entre el índice de Gini antes y después de las transferencias públicas

\begin{tabular}{|c|c|c|c|c|c|c|c|c|c|c|}
\cline { 2 - 11 } \multicolumn{1}{c|}{} & $\mathbf{2 0 0 8}$ & $\mathbf{2 0 0 9}$ & $\mathbf{2 0 1 0}$ & $\mathbf{2 0 1 1}$ & $\mathbf{2 0 1 2}$ & $\mathbf{2 0 1 3}$ & $\mathbf{2 0 1 4}$ & $\mathbf{2 0 1 5}$ & $\mathbf{2 0 1 6}$ & Promedio \\
\hline Unión Europea (UE-28) & -- & -- & 19,6 & 19,9 & 20,4 & 20,9 & 20,9 & 20,8 & 20,8 & 20,5 \\
\hline Unión Europea (UE-27) & 18,6 & 19 & 19,6 & 20 & 20,4 & 21 & 21 & 20,8 & 20,8 & 20,1 \\
\hline Eurozona & 18,5 & 18,5 & 19,3 & 19,8 & 19,9 & 20,6 & 20,9 & 20,8 & 20,9 & 19,9 \\
\hline España & 11 & 11,6 & 13,3 & 14,8 & 14,5 & 15,6 & 16,2 & 16,2 & 16,2 & 14,4 \\
\hline
\end{tabular}

\section{La pobreza relativa y sus características en términos comparados}

En este apartado, se cuantificarán las distintas modalidades de pobreza relativa mediante los índices creados por Eurostat ${ }^{16}$, se efectuará un análisis comparado entre España y sus socios europeos y, por último,

${ }^{15}$ Datos de Eurostat.

${ }^{16} \mathrm{La}$ variable refleja el porcentaje de la población que vive por debajo del $60 \%$ de la mediana de ingresos. 
se analizará el impacto del gasto público sobre dichos indicadores de pobreza relativa.

La tabla 6 muestra los porcentajes generales de pobreza antes y después de las transferencias monetarias realizadas por el Estado. A la luz de estos datos, se pueden extraer distintas conclusiones. En primer lugar, entre 2008 y 2016, la pobreza relativa de la sociedad española ha superado a la del conjunto de la Unión Europea y la eurozona. En segundo lugar, se observa una escasa eficacia del gasto público en términos de reducción de la pobreza, puesto que la diferencia entre el promedio de la pobreza antes y después de las transferencias públicas fue de tan sólo 7,2 puntos porcentuales.

Tabla 6. Porcentajes de pobreza antes y después de transferencias públicas (Promedio 2008-2016) ${ }^{17}$

\begin{tabular}{|l|c|c|c|c|}
\cline { 2 - 5 } \multicolumn{1}{c|}{} & $\begin{array}{c}\text { Unión } \\
\text { Europea a } \\
\text { 28 (UE-28) }\end{array}$ & $\begin{array}{c}\text { Unión } \\
\text { Europea a } \\
\mathbf{2 7} \text { (UE-27) }\end{array}$ & $\begin{array}{c}\text { Zona } \\
\text { Euro }\end{array}$ & España \\
\hline $\begin{array}{l}\text { \% Pobreza antes } \\
\text { transferencias } \\
\text { \% Pobreza después } \\
\text { transferencias } \\
\text { Diferencial }\end{array}$ & 25,9 & 25,9 & 25,7 & 29,5 \\
\hline
\end{tabular}

Por otra parte, si analizamos la magnitud de la pobreza por tramos de edad (tabla 7), también podemos deducir una serie de conclusiones. En cuanto a la pobreza registrada en el segmento de mayores de 65 años, en primer lugar, cabe destacar que es más o menos homologable a la del conjunto de la Unión Europea y la eurozona. De hecho, en el periodo estudiado, la pobreza relativa de los españoles de edad avanzada era inferior a la de sus socios europeos en términos

${ }^{17}$ Datos del Eurostat. 
agregados. En segundo lugar, las transferencias públicas son relativamente eficaces en cuanto a reducción de la pobreza se refiere. En cuanto a la pobreza relativa de los menores de 18 años, podemos concluir que su nivel es alarmantemente elevado, tanto en términos absolutos como en términos comparados. En efecto, en el periodo estudiado, la pobreza juvenil antes de transferencias superó en 1,7 puntos porcentuales al conjunto de la Unión y en 2,6 puntos a la eurozona. Por si esto fuese poco, la diferencia entre España y el conjunto de socios comunitarios se ensancha si observamos el porcentaje de pobreza relativa tras el efectuarse el gasto público $-8,7$ puntos respecto a la Unión Europea y 8,9 puntos respecto la eurozona-. En otras palabras, el gasto social realizado por las administraciones públicas españolas apenas reduce la tasa de pobreza relativa de aquellos menores de edad que residen en hogares situados bajo el umbral de la pobreza.

Tabla 7. Pobreza antes y después de transferencias por grupos de edad (Promedio 2008-2018) ${ }^{18}$

\begin{tabular}{|l|c|c|c|c|}
\cline { 2 - 5 } \multicolumn{1}{c|}{} & $\begin{array}{c}\text { Unión } \\
\text { Europea a 28 } \\
\text { (UE-28) }\end{array}$ & $\begin{array}{c}\text { Unión } \\
\text { Europea a } \\
\mathbf{2 7} \text { (UE-27) }\end{array}$ & $\begin{array}{c}\text { Zona } \\
\text { Euro }\end{array}$ & España \\
\hline $\begin{array}{l}\text { \% Pobreza antes transferencias } \\
\text { (mayores 65) } \\
\text { \% Pobreza después transferencias } \\
\text { (mayores 65) }\end{array}$ & 17,8 & 17,7 & 16,8 & 16,5 \\
Diferencial & 14,6 & 14,5 & 14,2 & 13 \\
\hline $\begin{array}{l}\text { \% Pobreza antes transferencias } \\
\text { (menores 18) } \\
\text { \% Pobreza después transferencias } \\
\text { (menores 18) }\end{array}$ & 3,2 & 3,2 & 2,6 & 3,5 \\
\hline \begin{tabular}{l} 
Diferencial \\
\hline
\end{tabular} & 34,3 & 34,3 & 33,4 & 36 \\
\hline
\end{tabular}

${ }^{18}$ Datos Eurostat. 
Si ponemos en relación el porcentaje de pobreza relativa y el gasto social como porcentaje del PIB, observamos una correlación negativa entre ambas variables. En otras palabras, contra mayor es el esfuerzo de inversión social de los estados, menor es la probabilidad de que registren altos índices de pobreza relativa. Una vez más, los estados se pueden agrupar en tres categorías: 1) Países de alto nivel de pobreza relativa y escaso gasto social -Rumania, Bulgaria y los países bálticos-; 2) Países con bajos niveles de pobreza relativa y altos niveles de inversión social -Holanda, Dinamarca, Suecia, Finlandia y Francia ${ }^{19}$; 3) Los países con niveles de inversión social moderadamente altos y altas tasas de pobreza relativa (Portugal, Grecia y España).

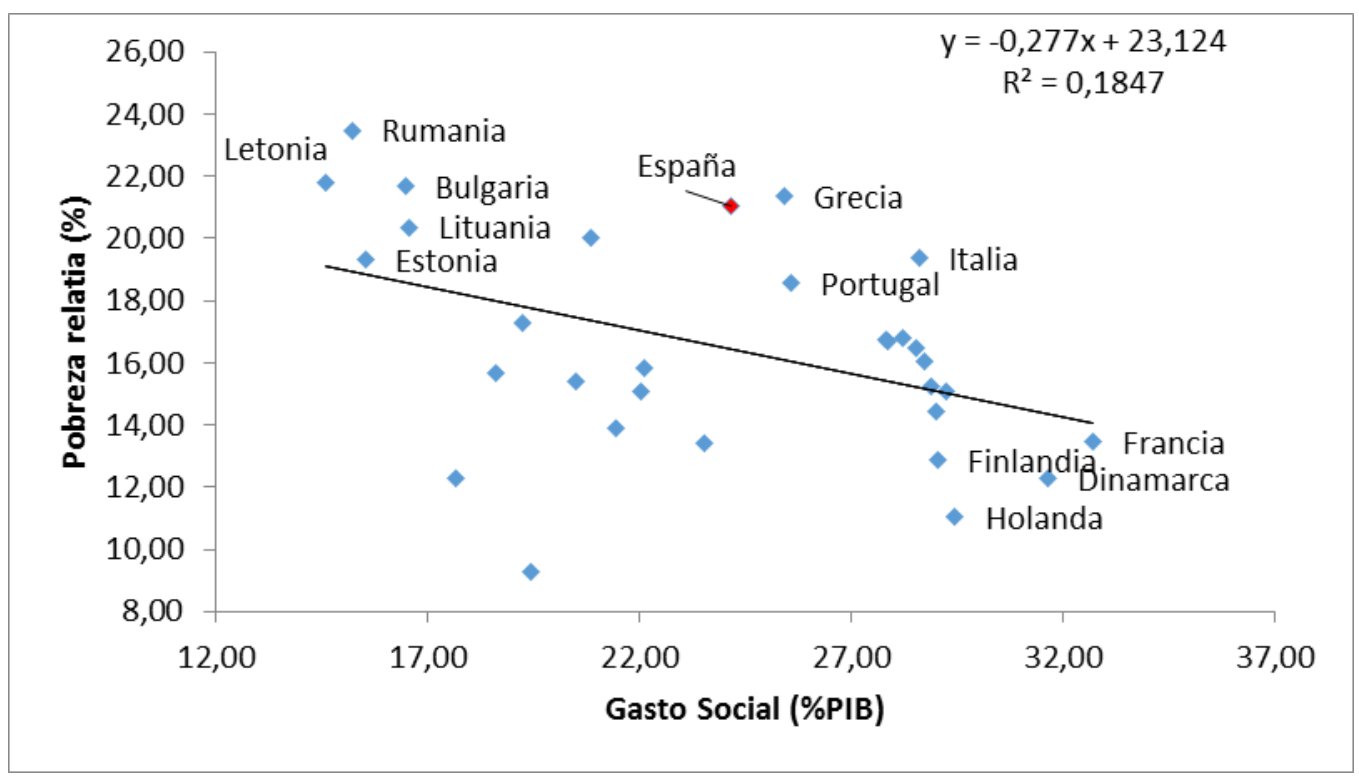

\section{Gráfico 8. Correlación entre el \%Pobreza relativa (Y) y el Gasto social $\%$ PIB (X)}

\footnotetext{
${ }^{19}$ Francia presenta una eficacia menor en términos de reducción de la pobreza que los países escandinavos. Sin embargo, su nivel de pobreza relativa es muy inferior al de los países del sur y del este de Europa.
} 


\section{Evolución y causas de la pobreza en España}

Una vez determinadas la dimensión absoluta y relativa de la pobreza, es preciso interrogarse acerca de su evolución y sus causas. El gráfico 9 revela que la pobreza relativa ha aumentado dos puntos y medio desde el inicio de la crisis. Además, el porcentaje de españoles que viven por debajo del umbral de la pobreza ha crecido de forma constante y casi ininterrumpida, puesto que, excepto en el periodo comprendido entre los años 2012 y 2013, se ha acrecentado año tras año. Por otra parte, en términos comparados, España ha pasado del sexto al tercer puesto a lo largo de este periodo en la escala de países con mayores tasas de pobreza relativa de la Unión.

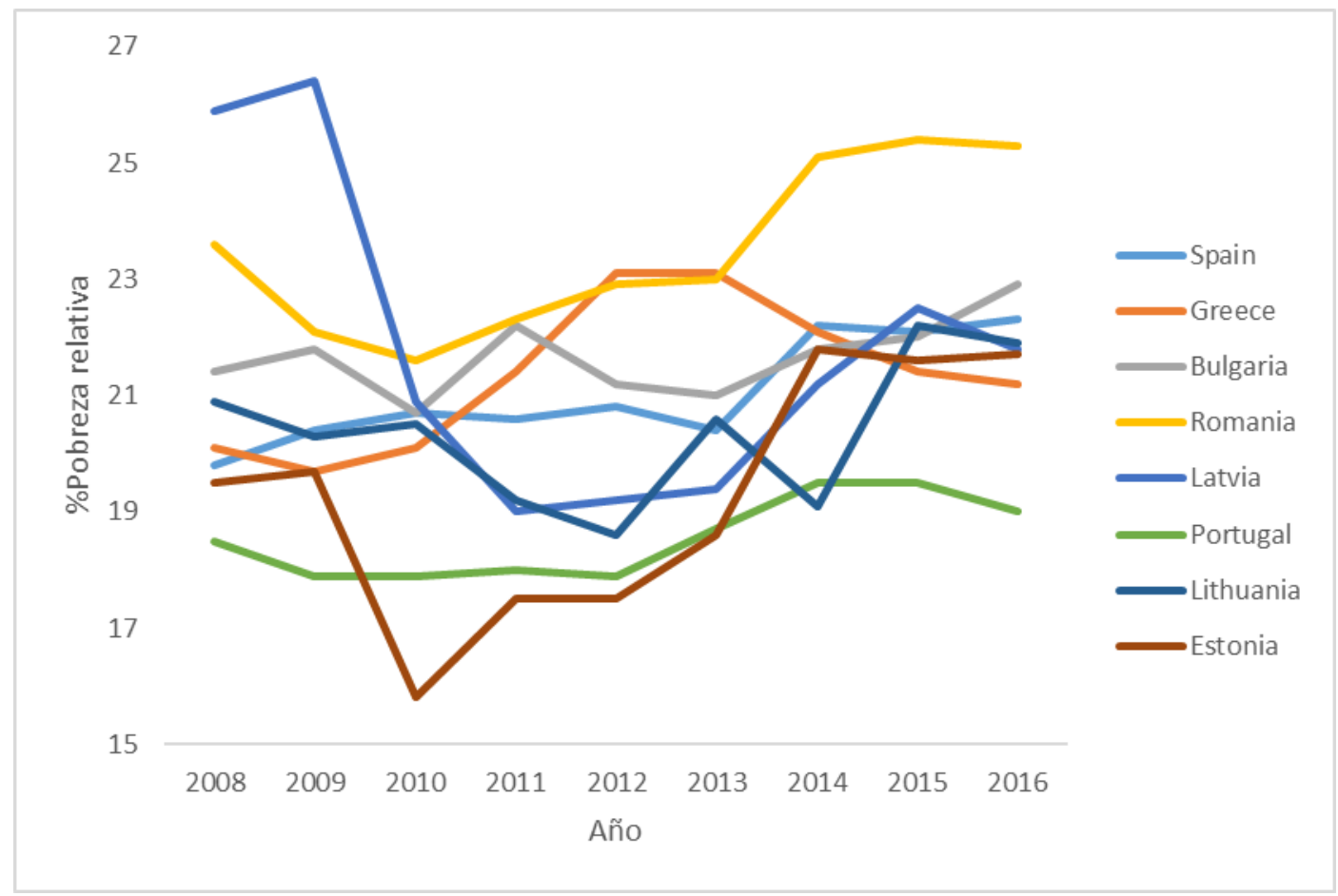

Gráfico 9. Evolución de la pobreza relativa (\%) 
Llegados a este punto, debemos preguntarnos por qué la pobreza se ha incrementado de forma tan notoria. Teniendo en cuenta los datos de la tabla dos, parece que el origen de este crecimiento vertiginoso ha sido el aumento del desempleo y su cronificación. Si bien esta proposición podría considerase cierta, es necesario observar también la evolución de los salarios. El gráfico 10 muestra la participación de los salarios en el Producto Interior Bruto (PIB). Como puede verse, hasta el segundo trimestre de 2010, el peso de los asalariados en el PIB se situó por encima del cincuenta por ciento pese a los altos niveles de desempleo. La única excepción relativa se produjo en el segundo trimestre de 2008 (49,88\% del PIB). Sin embargo, desde el tercer trimestre de 2010 al segundo trimestre del 2012, se produjo un deterioro paulatino, y no continuo, del peso de los salarios en el Producto Interior Bruto. Esta tendencia podría parecer casual, pero coincide con el periodo de vigencia del marco de relaciones laborales generado por la reforma laboral promovida por el PSOE. Por último, entre el segundo y el cuarto trimestre de 2012, la contribución salarial del PIB cayó prácticamente dos puntos pasando del 48,97\% al 46,99\%. Una vez más, el descenso abrupto de los salarios coincidió, no por casualidad, con un nuevo cambio normativo del marco de relaciones laborales (esta vez con el gobierno del PP). Desde entonces hasta el final del periodo estudiado, esta variable osciló entre el 47,89\% y el 46,63\%. En definitiva, a partir de 2013, la aportación salarial al PIB se ha estabilizado en niveles muy inferiores a los de antes de crisis. En buena medida, las dos reformas laborales han facilitado la reducción del precio de la fuerza de trabajo. 




\section{Gráfico 10. Participación de los asalariados en el PIB (\%) por trimestres ${ }^{20}$}

Si queremos saber cómo han afectado el paro y la depresión de los salarios a los distintos grupos de población, debemos analizar la evolución del porcentaje de la renta global acumulado por cada uno de los quintiles que componen a sociedad española (tabla 4) ${ }^{21}$. Como puede verse, los dos primeros quintiles experimentan una disminución de su contribución a la renta nacional durante este periodo. Sin embargo, los dos quintiles superiores registran mejoras relativas. Por lo que atañe al segmento intermedio de la población española, mantiene intacta su posición en relación al conjunto de la renta.

${ }^{20}$ Gráfico de elaboración propia a partir de la base de datos del Instituto Nacional de Estadística. (INE)

${ }^{21} \mathrm{El}$ orden de los quintiles es ascendente en términos de renta. Así pues, el primer quintil agrupa al 20\% de ciudadanos más pobres y el quinto quintil agrupa al 20\% más rico de la población. 
Tabla 8. Variación de la renta acumulada por grupos de población $(\%)^{22}$

\begin{tabular}{|l|c|c|c|c|c|c|c|c|c|}
\cline { 2 - 10 } \multicolumn{1}{c|}{} & $\mathbf{2 0 0 8}$ & $\mathbf{2 0 0 9}$ & $\mathbf{2 0 1 0}$ & $\mathbf{2 0 1 1}$ & $\mathbf{2 0 1 2}$ & $\mathbf{2 0 1 3}$ & $\mathbf{2 0 1 4}$ & $\mathbf{2 0 1 5}$ & Variación \\
\hline $\begin{array}{l}\text { Primer quintil } \\
\mathbf{( 0 - 2 0 \% )}\end{array}$ & 7,1 & 6,8 & 6,5 & 6,5 & 6,3 & 6,4 & 6 & 5,9 & $-1,2$ \\
\hline $\begin{array}{l}\text { Segundo } \\
\text { quintil (20- } \\
\mathbf{4 0 \% )}\end{array}$ & 12,7 & 12,7 & 12,7 & 12,4 & 12,4 & 12,5 & 12,2 & 12,3 & $-0,4$ \\
\hline $\begin{array}{l}\text { Tercer quintil } \\
\mathbf{( 4 0 - 6 0 \% )}\end{array}$ & 17,3 & 17,4 & 17,3 & 17,2 & 17,2 & 17,4 & 17,3 & 17,3 & 0 \\
\hline $\begin{array}{l}\text { Cuarto quintil } \\
\mathbf{( 6 0 - 8 0 \% )}\end{array}$ & 23,3 & 23,4 & 23,4 & 23,4 & 23,7 & 23,6 & 24 & 23,8 & 0,5 \\
\hline $\begin{array}{l}\text { Quinto quintil } \\
\mathbf{( 8 0 - 1 0 0 \% )}\end{array}$ & 39,6 & 39,7 & 40,1 & 40,5 & 40,5 & 40,1 & 40,6 & 40,6 & 1 \\
\hline
\end{tabular}

Si analizamos la variación de la contribución a la renta nacional por quintiles y en cada uno de los periodos de este ciclo, hallamos un resultado claro. El único sector que se ha empobrecido en todos los intervalos de tiempo ha sido el primer quintil. Además, los dos primeros quintiles son los únicos que no han mejorado su posición en ninguno de los periodos estudiados. En cuanto al sector intermedio de la sociedad (tercer quintil), mantuvo su rango durante los primeros años de la crisis y sufrió un retroceso entre los años 2010 y 2012. No obstante, mejoró su posición en la fase final de la crisis económica. Por último, conviene destacar que la renta acumulada por los dos quintiles más pudientes de la sociedad ha experimentado un crecimiento sostenido, si bien este ha sido más moderado en la fase final del ciclo analizado.

${ }^{22}$ Tabla de elaboración propia a partir de la base de datos de la OCDE. 


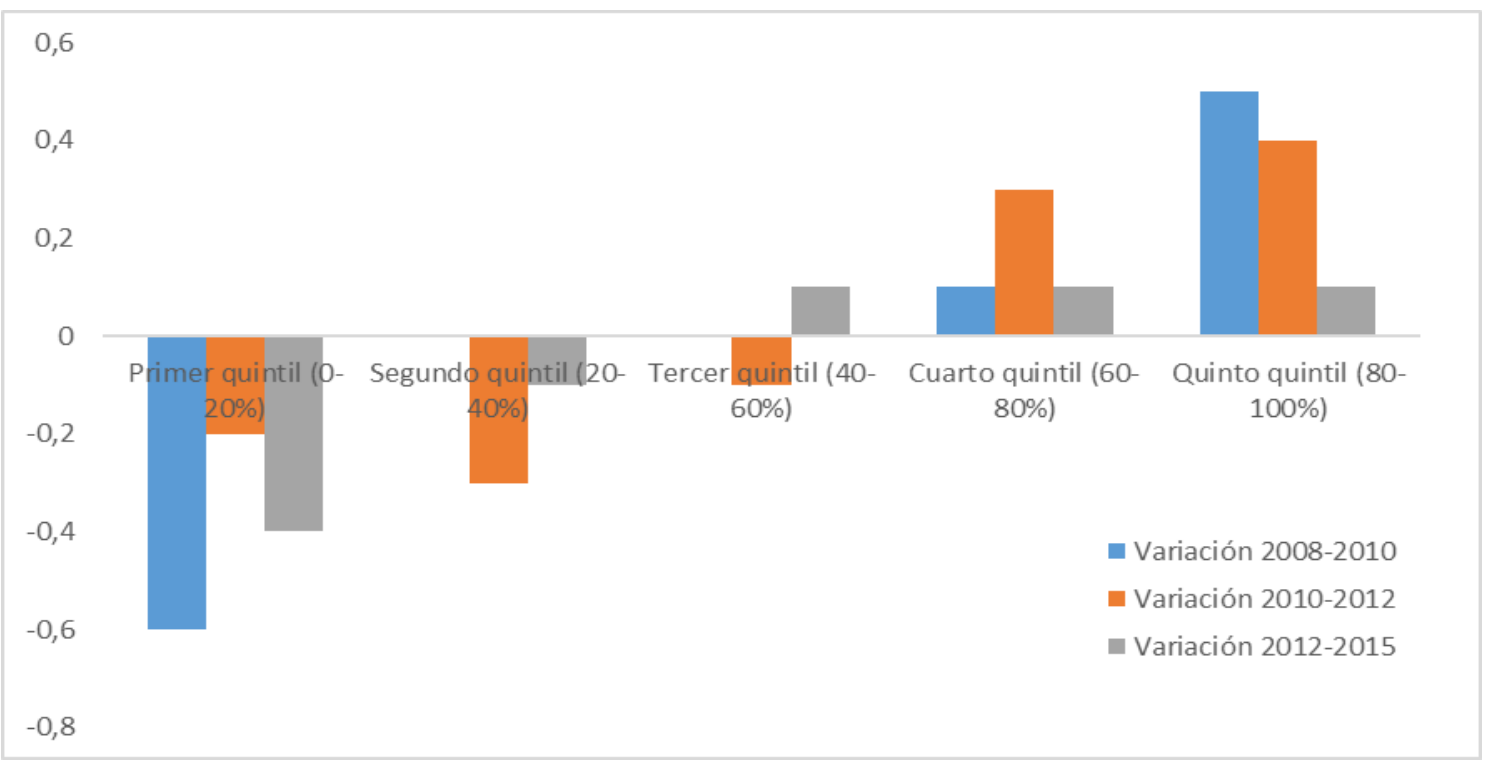

Gráfico 11. Variación de la contribución a la renta nacional por quintiles y periodos $(\%)^{23}$

\section{Composición y eficacia del gasto público}

Recapitulando sobre los datos anteriores, vemos que en los últimos años el mercado de trabajo ha producido un empobrecimiento de los estratos más bajos de la sociedad y una transferencia de rentas hacia los sectores más pudientes. Las clases medias han visto peligrar su posición, pero ésta ha resultado proporcionalmente menos mermada. A su vez, el gasto público no ha sido capaz de mitigar el crecimiento de las desigualdades y la pobreza y, además, se ha mostrado peculiarmente ineficiente para ello, comparado con los países de nuestro entorno. Para identificar las carencias estructurales de nuestro gasto social, debemos analizar su composición en términos absolutos y comparados.

${ }^{23}$ Gráfico elaborado a partir de la base de datos de la OCDE.

B 
El gasto social se puede dividir en dos grandes bloques: el gasto social en servicios y el gasto social en transferencias. En este artículo, nos centraremos en el segundo tipo de gasto, porque es el que incide sobre la desigualdad y la pobreza medidas en términos de ingreso. Según datos de la OCDE, España es el octavo país con mayor gasto en transferencias. Como puede verse en el gráfico 12, los países del sur de Europa (España, Portugal, Italia y Grecia) están cerca de países como Finlandia, Bélgica o Francia en cuanto a gasto en transferencias se refiere.

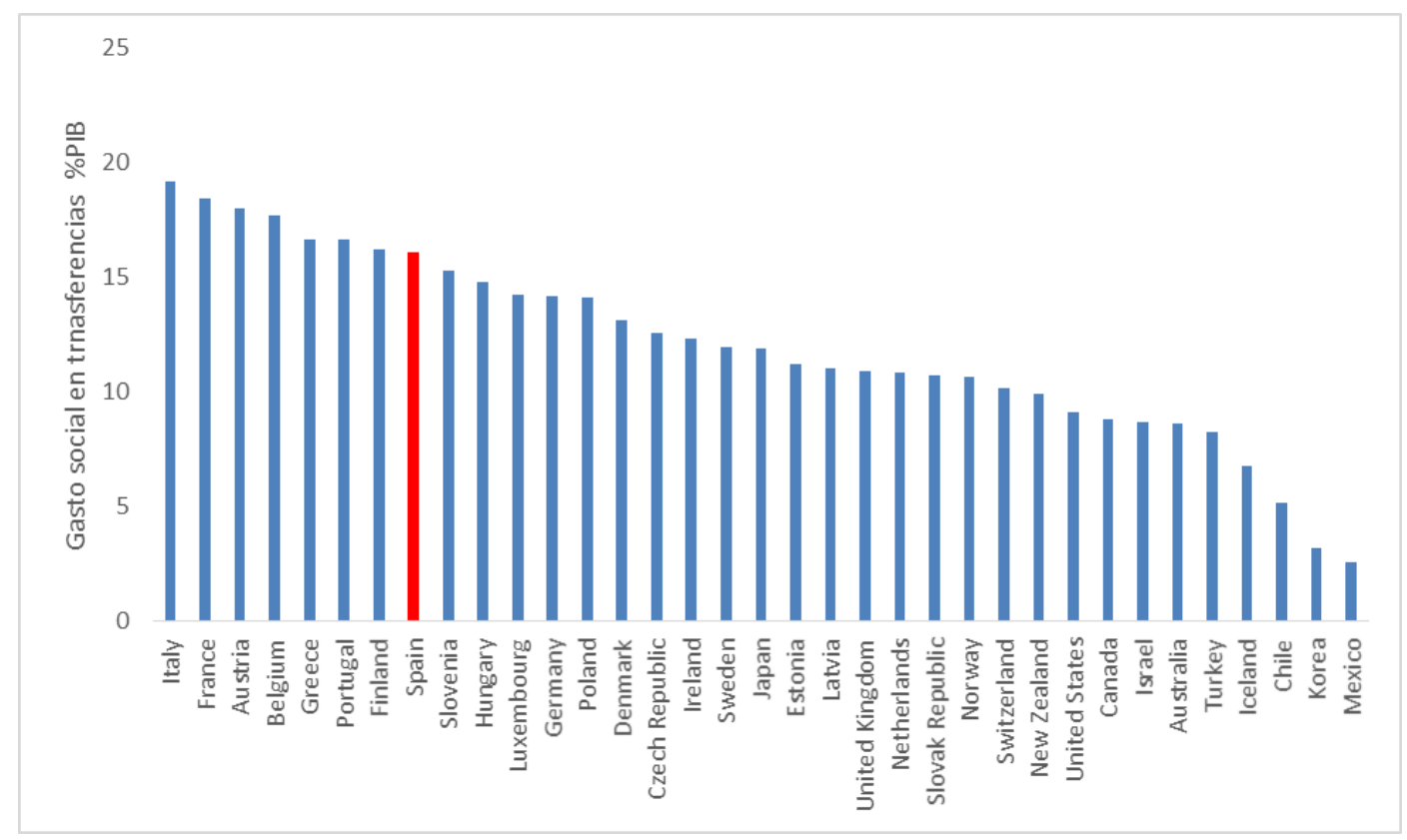

Gráfico 12. Gasto en transferencias \% PIB (2008-2013) ${ }^{24}$

Como puede verse en a tabla 5, si lo comparamos con la media de los países de la OCDE, nuestro país invierte mucho en tercera edad y

${ }^{24}$ Gráfico elaborado a partir de la base de datos de la OCDE.

B ANUARI DEL CONFLICTE SOCIAL 2017 
mercado laboral. En cuanto a salud y discapacidad, invierte más que la media de países desarrollados, aunque la diferencia no es demasiado notoria. Como se ha dicho anteriormente, este artículo no toma en consideración el gasto social en servicios. Por lo tanto, obviaremos el gasto en servicios de salud y nos centraremos en las principales partidas de gasto en transferencias (tercera edad, mercado laboral y salud).

Tabla 9. Gasto social según tipología $(\% \mathrm{PIB})^{25}$

\begin{tabular}{|l|ccccccc|}
\cline { 2 - 8 } \multicolumn{1}{c|}{} & $\begin{array}{c}\text { Tercera } \\
\text { edad }\end{array}$ & Salud & Familia & Discapacidad & $\begin{array}{c}\text { Mercado } \\
\text { laboral }\end{array}$ & $\begin{array}{c}\text { Otros } \\
\text { gastos } \\
\text { sociales }\end{array}$ & Vivienda \\
\hline España & 12,0 & 6,4 & 1,3 & 2,5 & 3,7 & 0,2 & 0,1 \\
OCDE & 8,8 & 6,0 & 2,0 & 2,0 & 1,3 & 0,5 & 0,3 \\
Diferencia & 3,2 & 0,4 & $-0,7$ & 0,5 & 2,4 & $-0,2$ & $-0,2$ \\
\% Diferencia & 136,00 & 106,91 & 65,60 & 126,10 & 283,01 & 51,46 & 29,42 \\
\hline
\end{tabular}

En cuanto al gasto social en pensiones de jubilación (gráfico 13), España es el octavo país que más inversión realiza. Este dato explicaría, hasta cierto punto, los índices de pobreza relativamente bajos entre los mayores de 65 (tabla 7).

${ }^{25}$ Tabla de elaboración propia a partir de la base de datos de la OCDE. 


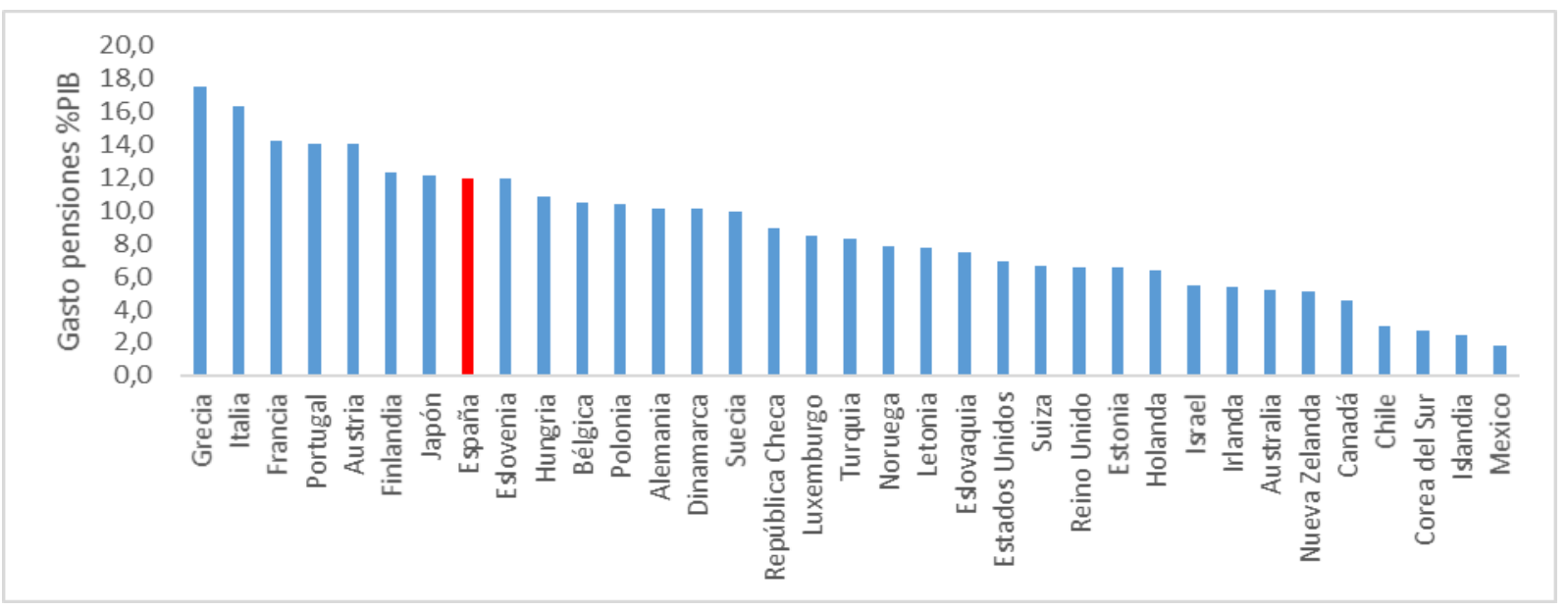

\section{Gráfico 13. Gasto social en pensiones \% $\% \mathrm{~PB}^{26}$}

En cuanto al desempleo (Grafico 14), España se sitúa en la segunda posición en el ranking de los países que más gasta. Sin embargo, este gasto es una variable dependiente de la tasa de desempleo. Teniendo en cuenta que España es el segundo país con mayor nivel de desempleo (gráfico 15), el gasto en políticas de empleo (activas o prestaciones por desempleo) no parece demasiado alto. De hecho, si correlacionamos las dos variables (gráfico 16), podemos constatar varias cosas. En primer lugar, existe una correlación directa y positiva entre ambas variables. Dicho de otro modo, a mayores niveles de desempleo, mayor inversión en políticas de mercado laboral. En segundo lugar, Grecia y España presentan niveles de paro anormalmente elevados. En tercer lugar, los parados españoles e italianos perciben unas cuantías relativamente elevadas en comparación a los de otros países con niveles de paro altos o moderadamente altos (Grecia y Portugal).

${ }^{26}$ Gráfico elaborado a partir de la base de datos de la OCDE.

$\underset{\mathrm{B}}{\mathrm{C}}$ 


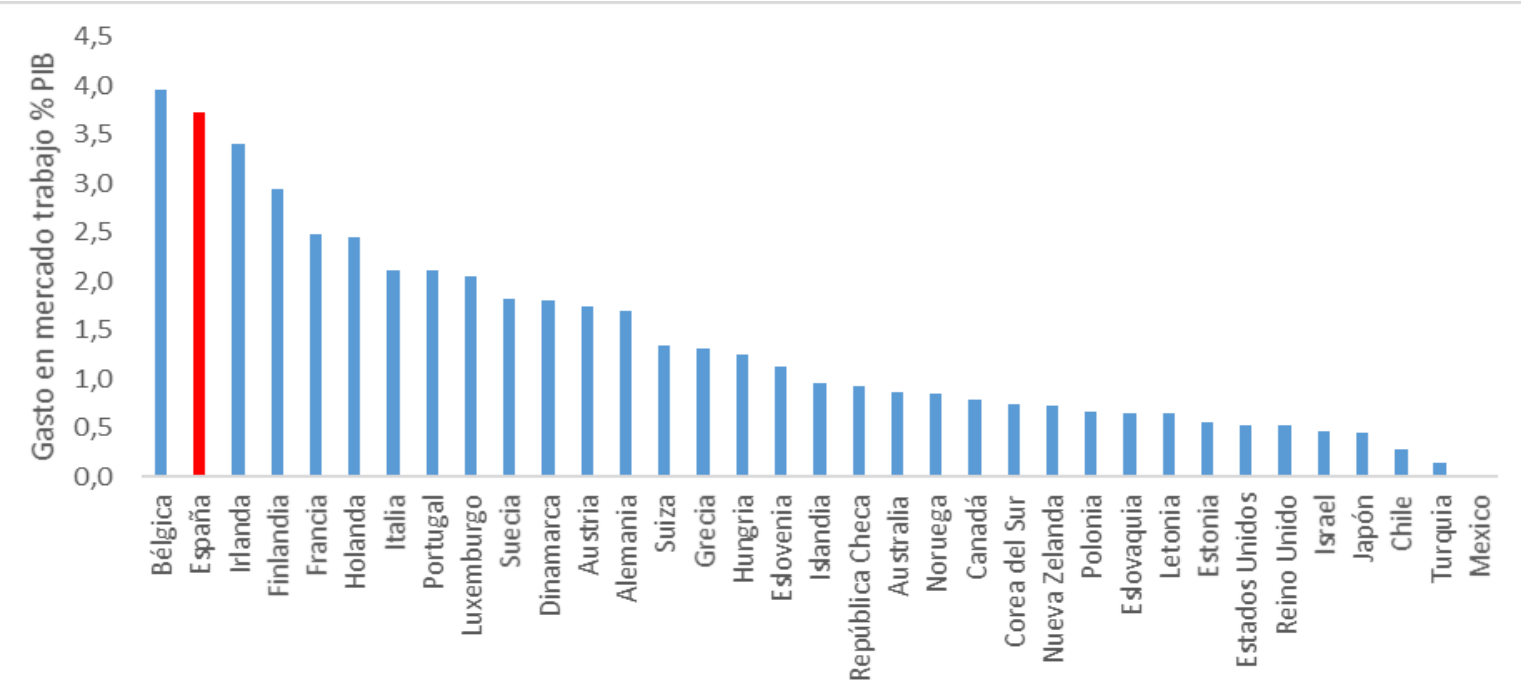

Gráfico 14. Gasto en mercado de trabajo como \% PIB (prestaciones más políticas activas de empleo) ${ }^{27}$

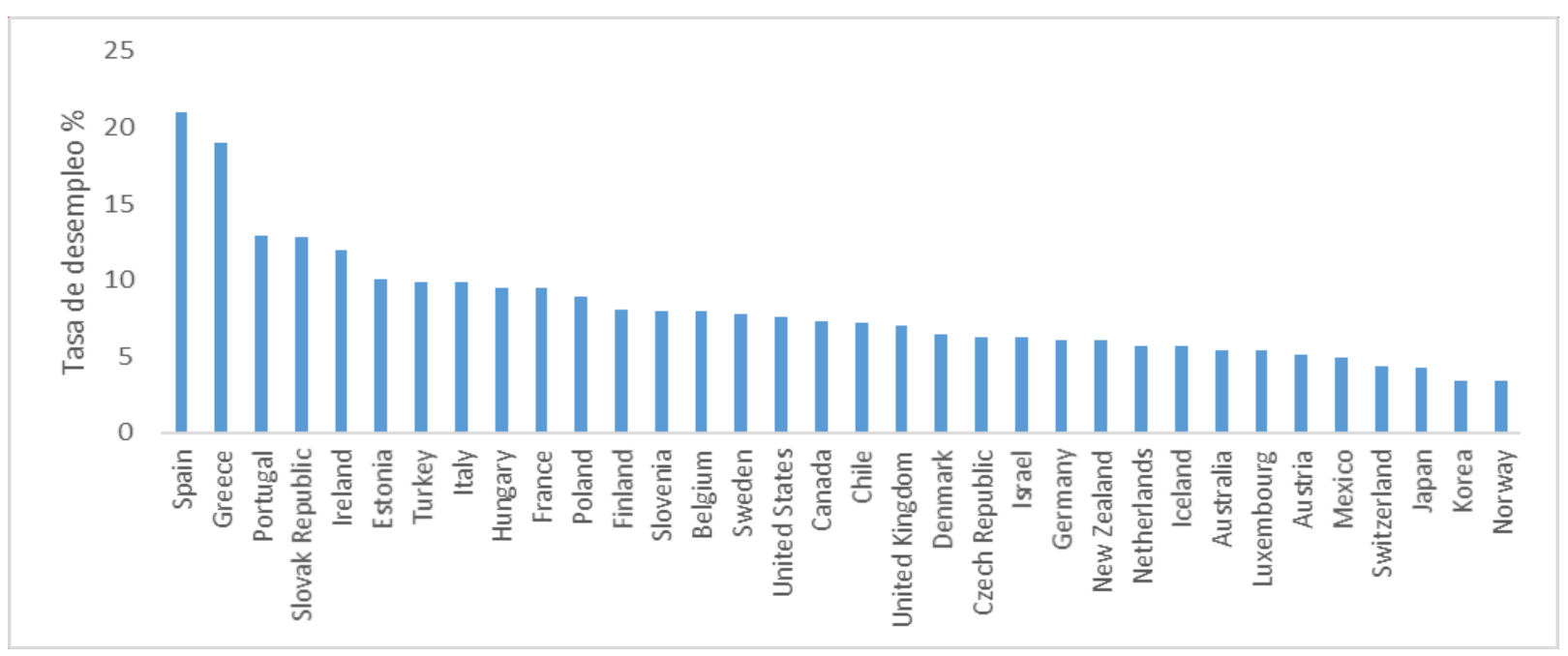

Gráfico 15 . Tasa de desempleo $(\%)^{28}$

27 Gráfico elaborado a partir de la base de datos de la OCDE.

U)

B ANUARI DEL CONFLICTE SOCIAL 2017 


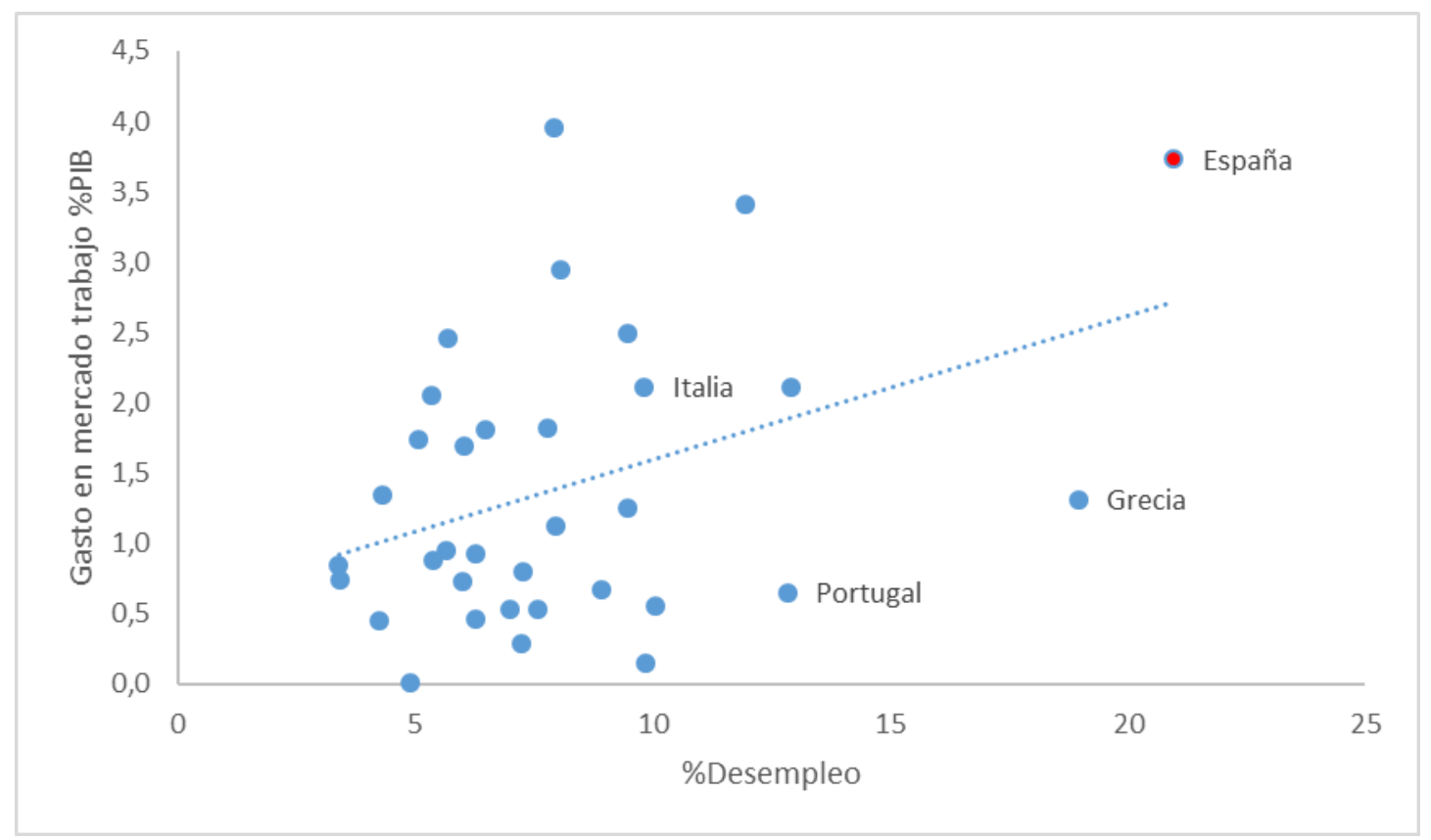

\section{Gráfico 16. Correlación entre gasto en mercado de trabajo y} desempleo $^{29}$

Por último, en cuanto al gasto en familia, España es el onceavo país de la OCDE que menos esfuerzo de inversión realiza. Además, se encuentra muy lejos de los países con mayores niveles de gasto $-2,5$ puntos porcentuales respecto del Reino Unido; 2,4 respecto a Dinamarca y 2,3 respecto Suecia, Islandia y Luxemburgo- y a casi 0,8 puntos de la mediana de la OCDE $(2,05 \%$ del PIB).

28 Gráfico elaborado a partir de la base de datos de la OCDE. No hay datos de paro de Letonia.

${ }^{29}$ Gráfico elaborado a partir de la base de datos de la OCDE. 


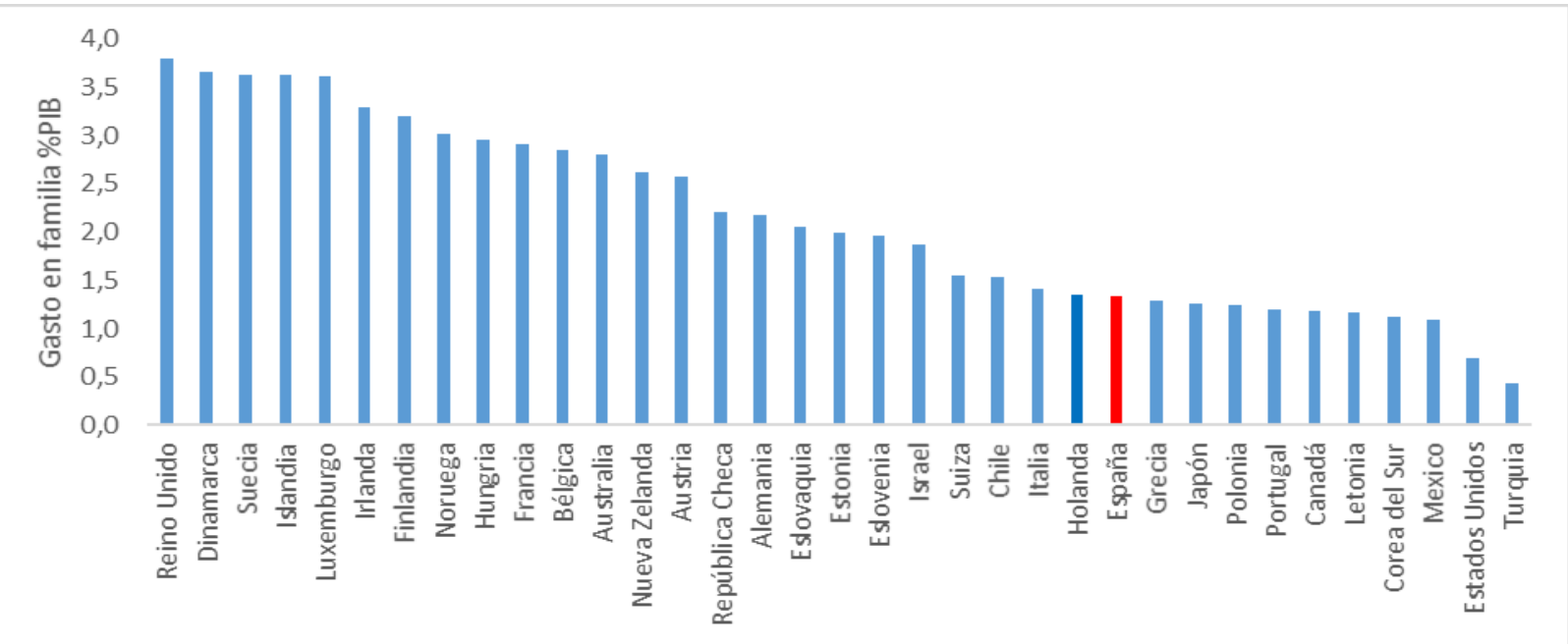

\section{Gráfico 17 . Gasto en familia $(\% \text { PIB })^{30}$}

En definitiva, la mayor parte de países desarrollados realizan grandes inversiones sociales cuyos beneficiarios son personas en edad de trabajar. En cambio, España tiene un importante déficit en este tipo de inversiones. Concretamente, su gasto en familia es alarmantemente bajo. Teniendo en cuenta que la mayor parte de perceptores de este tipo de transferencias son los sectores más empobrecidos de la sociedad, el gasto en familia reduce considerablemente las desigualdades (gráfico 18).

${ }^{30}$ Gráfico elaborado a partir de la base de datos de la OCDE.

B 


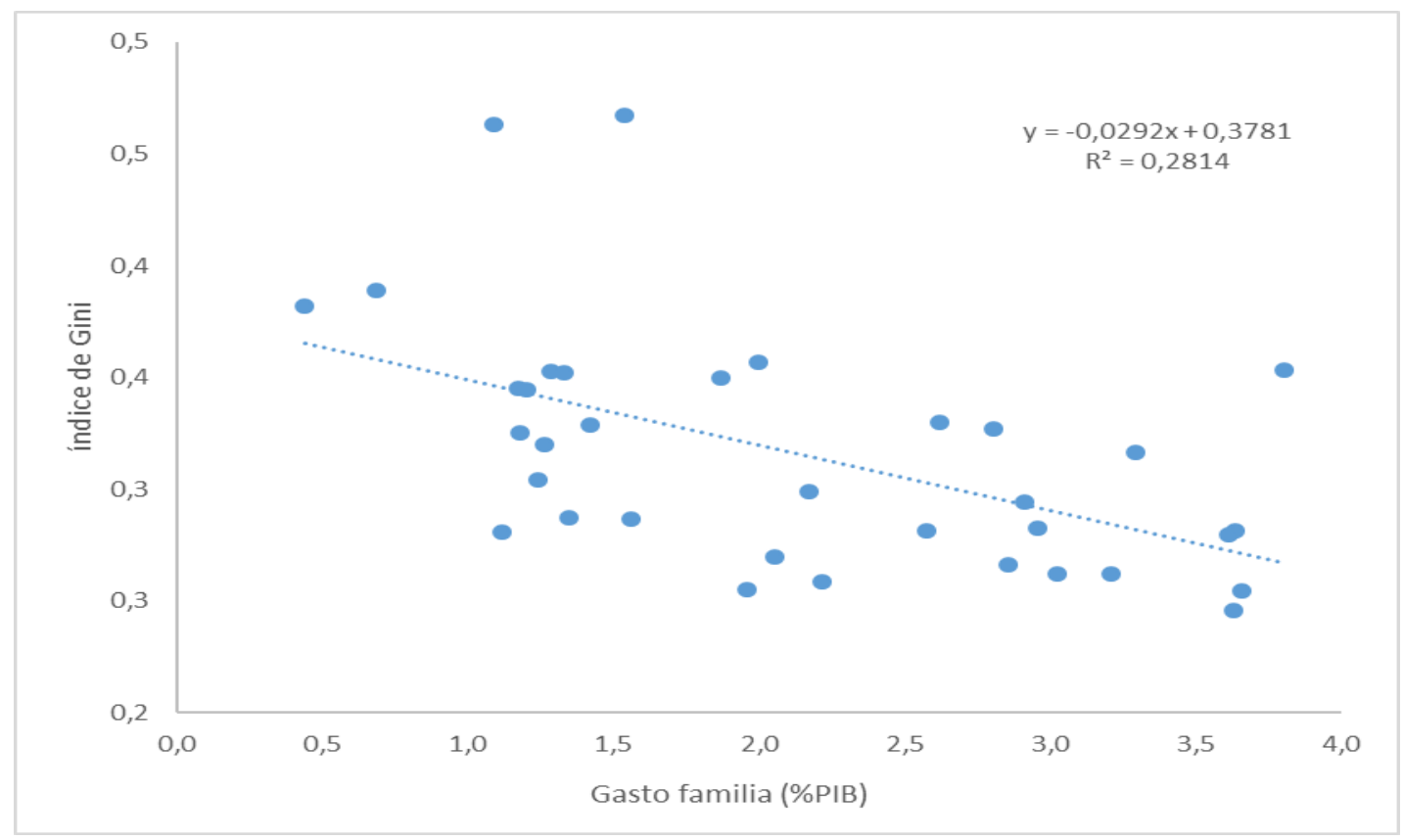

Gráfico 18. Correlación entre el gasto en familia y el índice de Gini $^{31}$

Además de lo anterior, las transferencias públicas en familia se financian a través de los presupuestos generales del estado cuyo sustento principal son los impuestos directos sobre la renta. Así pues, sus principales sustentadores son las clases medias y altas y sus principales perceptores son las rentas más bajas. Sin embargo, las pensiones y las prestaciones por desempleo se financian a través de cotizaciones. Teniendo en cuenta que su cuantía económica es directamente proporcional a las aportaciones previas de los contribuyentes, este segundo tipo de transferencias no son, por su propia definición, progresivas. Por lo tanto, en aquellas sociedades en

${ }^{31}$ Gráfico elaborado a partir de la base de datos de la OCDE.

B

ANUARI DEL CONFLICTE SOCIAL 2017 
que el gasto principal en transferencias lo formen las prestaciones contributivas -por ejemplo: España, Grecia, Portugal e Italia-, el gasto social será regresivo o escasamente progresivo. Este efecto se puede comprobar analizando el porcentaje del gasto social recibido por cada percentil. En el gráfico 19, muestra los países de la OCDE según el porcentaje del gasto social en transferencias recibido por el quintil inferior de la población. Como puede verse, en los países del sur de Europa y Polonia, las proporciones percibidas por el sector más desfavorecido de la sociedad son irrisorias.

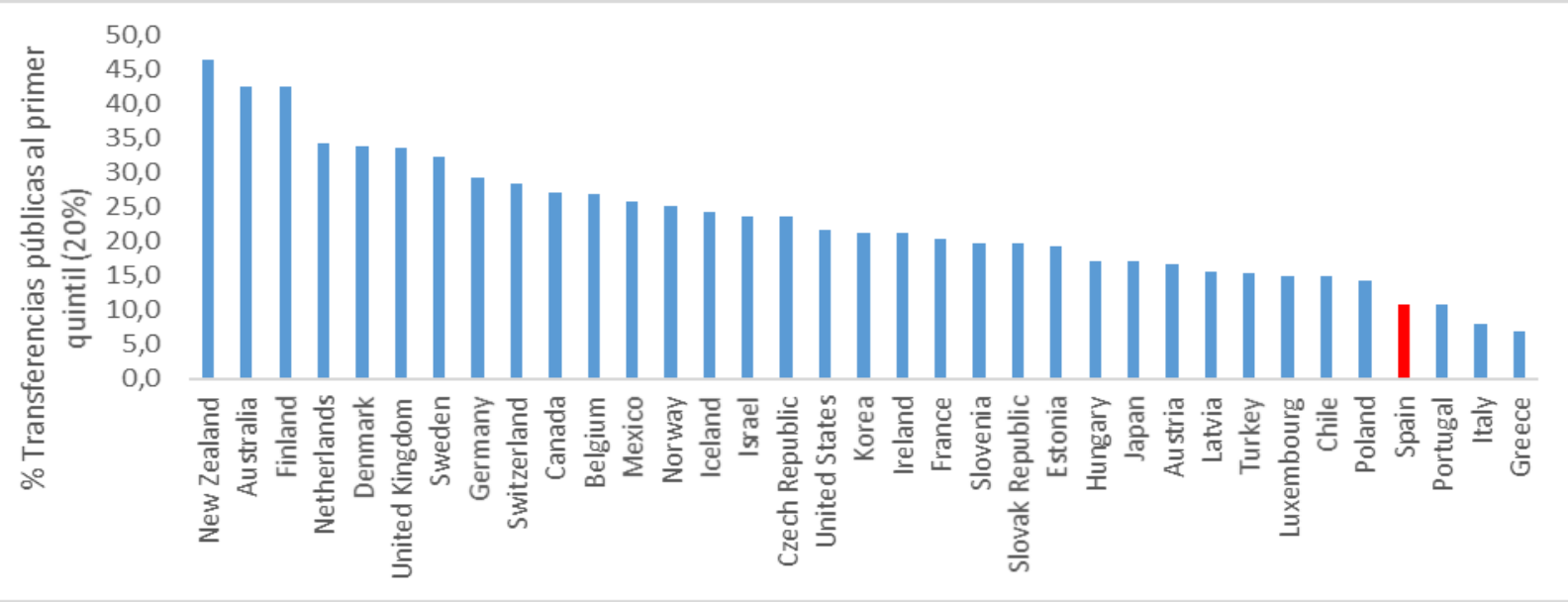

Gráfico 19. Porcentaje de transferencias públicas percibidas por el primer quintil (promedio 2008-2015) ${ }^{32}$

Si comparamos las percepciones en transferencias del primer y el último quintil (gráfico 20), el resultado llama mucho la atención. En la mitad de los países desarrollados, el sector más pudiente de la sociedad recibe un mayor porcentaje del gasto en tranferencias. La diferencia entre estos dos porcentajes es epecialmente abultada en Turquia,

${ }^{32}$ Gráfico elaborado a partir de la base de datos de la OCDE.

B 
Méjico, Grecia, Italia, España y Portugal. En los dos primeros, el gasto en transferencias es muy inferior al de la mayoría de países avanzados, pues no han desarrollado el estado social. En los otros tres casos, estamos hablando de países con un nivel de gasto considerable, aunque escasamente progresivo.

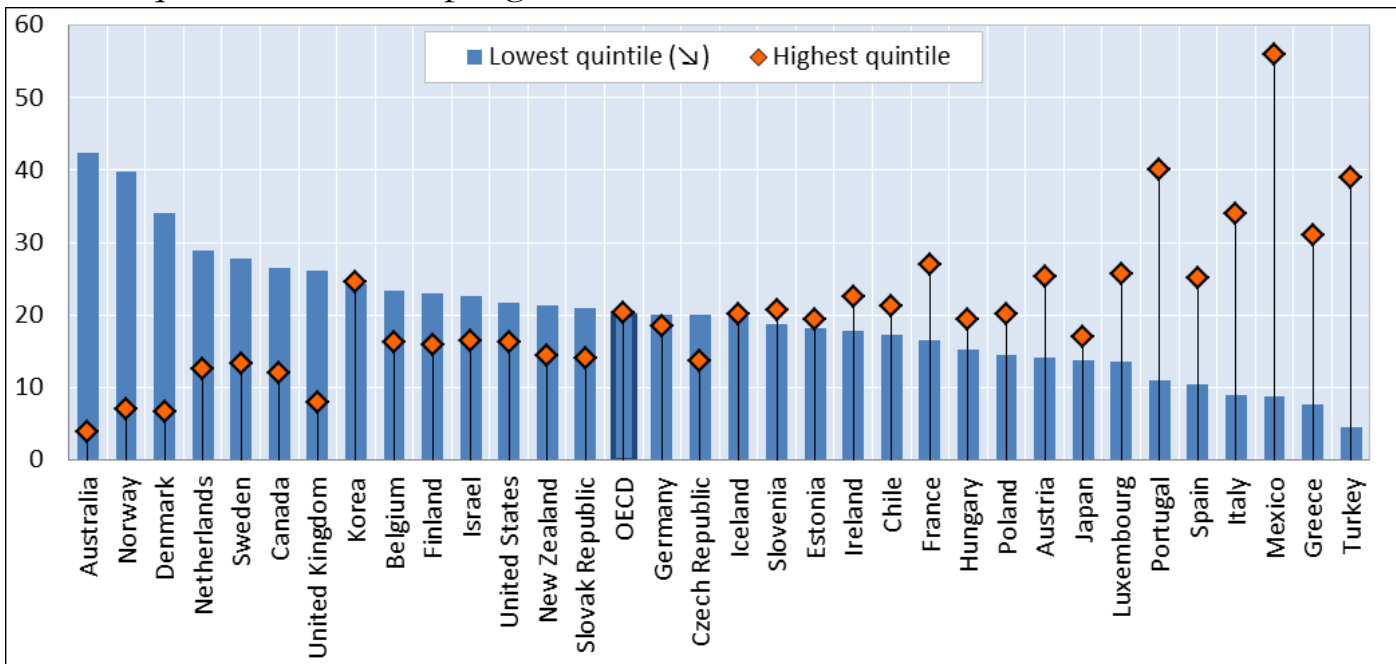

Gráfico 20. Porcentaje del gasto en transferencias recibido el primer y el último quintil (año 2011) ${ }^{33}$.

Por último, es necesario analizar la evolución de los distintos tipos de gasto en transferencias (tabla 5). Si nos centramos en las transferencias dirigidas a la población en edad de trabajar, podemos observar dos cosas. En primer lugar, el gasto en políticas de empleo creció durante el primer lustro coincidiendo con el aumento de la tasa de desempleo y se redujo en el segundo como consecuencia de una tenue recuperación del empleo. En segundo lugar, las transferencias en familia también aumentaron en el lustro 2005-2009. Una de las medidas de apoyo a las

33 Gráfico extraído del informe social Expenditure Update 2014 elaborado por la OCDE. 
familias más conocidas fue el llamado "chequé bebé"34. Sin embargo, en el lustro siguiente, este tipo de transferencias se redujo en un 3,7\% respecto al periodo anterior a pesar del incremento de la pobreza y la desigualdad. Este hecho contrasta con lo ocurrido en la mayor parte de países de la OCDE, en los cuales el gasto en familia no dejó de crecer entre 2010 y 2014. Esto resulta más sorprendente todavía i tenemos en cuenta que, en su mayoría, no registraron tasas de desempleo tan elevada como la de nuestro país.

\section{Tabla 10. Incremento porcentual del gasto en España y en la media de países de la OCDE (\%) ${ }^{35}$}

\begin{tabular}{|l|c|c|c|c|c|c|}
\cline { 2 - 7 } \multicolumn{1}{c|}{} & \multicolumn{2}{c|}{ Tercera edad } & \multicolumn{2}{c|}{$\begin{array}{c}\text { Mercado laboral } \\
\text { prestaciones y PAE) }\end{array}$} & \multicolumn{2}{c|}{ Familia } \\
\cline { 2 - 7 } & $\mathbf{2 0 0 5 - 2 0 0 9}$ & $\begin{array}{c}\mathbf{2 0 1 0 -} \\
\mathbf{2 0 1 3 / 1 4}\end{array}$ & $\mathbf{2 0 0 5 - 2 0 0 9}$ & $\begin{array}{c}\mathbf{2 0 1 0}- \\
\mathbf{2 0 1 3 / 1 4}\end{array}$ & $\mathbf{2 0 0 5 - 2 0 0 9}$ & $\begin{array}{c}\mathbf{2 0 1 0}- \\
\mathbf{2 0 1 3} / \mathbf{1 4}\end{array}$ \\
\hline España & 5,4 & 3,5 & 13,1 & $-4,0$ & 8,4 & $-3,7$ \\
OCDE & 4,20 & 3,20 & 11,65 & $-1,89$ & 6,52 & 0,76 \\
\hline
\end{tabular}

\section{La desigualdad social en la opinión publica}

Los barómetros trimestrales publicados por el Centro de Investigaciones Sociológicas (CIS) suelen preguntar a los españoles cuáles son los principales problemas que sufre el país. En estos últimos años, los asuntos percibidos como más problemáticos han sido el paro y las cuestiones de índole económica. Sin embargo, el CIS no acostumbra a preguntar sobre las desigualdades sociales y el papel del Estado frente a éstas. No obstante, en septiembre de 2011, incluyó algunas preguntas relacionadas con la desigualdad. La primera de ellas era cuáles debían ser los objetivos España en los próximos diez años

\footnotetext{
${ }^{34}$ Fue una prestación no contributiva de 2.500 euros que recibieron las familias por cada hijo nacido o adoptado entre el julio de 2007 y diciembre de 2010.

${ }^{35}$ Datos OCDE.
} 
(Tabla 6). Para el 71,3\% de los encuestados, el principal objetivo de los poderes públicos debía ser la lucha contra el desempleo. A mucha distancia, el ocho por ciento respondió que el objetivo primordial debía ser la lucha contra las desigualdades. A la pregunta sobre cuál debía ser el segundo de los objetivos a perseguir en los próximos diez años, el 23,1\% de los encuestados consideraba que debía ser la lucha contra la desigualdad social. Así pues, la reducción de las desigualdades era considerada, en buena medida, como uno de los principales retos del país.

Cuando se preguntaba a los encuestados sobre el rol que debía adoptar el estado frente a las desigualdades, la mayoría respondía que éste debía garantizar un nivel mínimo de vida para todos los ciudadanos (Tabla 7). Por otra parte, el 16,7\% consideraba que la labor principal del estado debía ser promover el crecimiento económico, aunque ello supusiese incrementar las desigualdades y solamente un 15,4\% opinaba que el estado debía adoptar un rol activo en la disminución de las desigualdades. En definitiva, si bien las desigualdades sociales eran consideradas como un problema por buena parte de la sociedad española, la mayoría de encuestados pensaba que el objetivo principal del estado, en su actuación sobre estas cuestiones, no debía consistir en reducir la brecha entre ricos y pobres, sino en garantizar la igualdad de oportunidades $(29,4 \%)$ y en asegurar un nivel de bienestar mínimo para todos los ciudadanos (35\%). Teniendo en cuenta el elevado porcentaje encuestados que estimaba necesario promover el crecimiento económico, podemos concluir que buena parte de los españoles confían en el progreso económico y en el empleo como medios para mejorar la inserción social de los sectores desfavorecidos. 
Tabla 11. Principales objetivos de España en los próximos 10 años (CIS, setiembre 2011)

\begin{tabular}{|l|cc|}
\cline { 2 - 3 } \multicolumn{1}{c|}{} & Principal & En segundo lugar \\
\hline La lucha contra el terrorismo & 5,8 & 10,5 \\
La protección del medio ambiente y la & & \\
naturaleza & 4,6 & 14,7 \\
La lucha contra la delincuencia & 2,2 & 7,1 \\
La lucha contra el paro & 71,3 & 17,2 \\
Controlar la inmigración & 5 & 20,1 \\
La lucha contra las desigualdades & 8 & 23,1 \\
Otro objetivo & 1,9 & 2,8 \\
N.S. & 0,9 & 3,1 \\
N.C. & 0,2 & 1,4 \\
\hline
\end{tabular}

Tabla 12. Rol del estado frente a las desigualdades sociales (CIS, setiembre 2011)

\begin{tabular}{|l|c|}
\cline { 2 - 2 } \multicolumn{1}{l|}{} & $\mathbf{\%}$ \\
\hline $\begin{array}{l}\text { Promover el crecimiento económico independientemente de que } \\
\text { algunas de que algunas }\end{array}$ & 16,7 \\
personas se beneficien más que otras & 35 \\
Garantizar un nivel de vida mínimo para todas las personas \\
$\begin{array}{l}\text { Reducir las diferencias de ingresos entre las personas ricas y las } \\
\text { personas pobres }\end{array}$ & 15,4 \\
Tratar de asegurarse de que haya igualdad de oportunidades para & 29,4 \\
salir todas las personas adelante & 2,7 \\
N.S. & 0,8 \\
\hline
\end{tabular}

Por último, la mayoría de encuestados prefería incrementar el gasto público, aunque ello significase pagar más impuestos (tabla 8). Así 
pues, si hiciésemos extensivo el resultado de la encuesta al conjunto de la población, la mayor parte de españoles estaría dispuesto a garantizar una mejor inserción social de las personas desfavorecidas mediante el presupuesto público, aunque la diferencia sobre aquellos que prefieren ver reducida la carga fiscal a costa de mejores niveles de protección social es tan sólo de 1,8 puntos porcentuales.

Tabla 13. Preferencias de los españoles en relación a las medidas que debe adoptar el Gobierno (CIS, setiembre 2011)

Es preferible bajar los impuestos, aunque esto signifique gastar menos en prestaciones sociales y servicios públicos

Es preferible gastar más en prestaciones sociales y servicios públicos, aunque eso signifique pagar más impuestos

N.S

$\%$

N.C

6.1

\section{Analizando detenidamente las pensiones}

Como se ha dicho anteriormente, España es el octavo país de la OCDE con mayor gasto en pensiones (gráfico 13). Este gran esfuerzo de inversión social consigue reducir los índices de pobreza de los sectores de población de edad más avanzada de forma significativa (tabla 7). Por otra parte, según datos del INE, la pensión media aumentó un 26,40\% entre octubre de 2010 y enero de 2017 pasando de los 668,16 a los 907,77 euros al mes. Mientras tanto, el Índice de Precios de Consumo (IPC) se incrementó solamente un 16,1\%. Por lo tanto, podemos concluir que, a diferencia de los salarios, la pensión media en España se ha ido revalorizando de forma progresiva.

Sin embargo, si realizamos un análisis más pormenorizado de las pensiones en España, se observan una serie de desequilibrios 
preocupantes. La tabla 9 muestra una distribución del número de beneficiarios según la cuantía de la pensión que perciben. Entre los pensionistas que reciben pensiones de jubilación, se pueden observar cuatro datos muy curiosos. En primer lugar, el número de perceptores aumenta paulatinamente hasta llegar a los 655,19 euros al mes. En segundo lugar, a partir de los 700 euros, el número de perceptores empieza a disminuir. En tercer lugar, se puede constatar un déficit considerable de pensionistas en el tramo de los 700,01 a los 1100 euros/mes. En cuarto y último lugar, el número de pensionistas situados en el tramo de los 2000,01 a los 2567,29 euros/mes es anormalmente elevado. En cuanto a las pensiones de viudedad, hay tres tramos relevantes: 1) El que percibe entre 150,01 y 500 euros al mes (el 29,70\% de los perceptores); 2) El que percibe entre 500,01 y 655,19 euros al mes (36,39\% de los perceptores) y 3) El que recibe entre 700,01 y 1100 euros al mes (20,21\%).

Tabla 14. Beneficiarios de pensiones de jubilación y viudedad según cuantía (año de referencia 2016) ${ }^{36}$

\begin{tabular}{|c|c|c|c|c|c|c|c|c|c|c|}
\hline & $\begin{array}{c}\text { Hasta } \\
150 \\
\text { Euros }\end{array}$ & $\begin{array}{c}\text { De } \\
150,01 \\
\text { a 500 } \\
\text { Euros }\end{array}$ & $\begin{array}{c}\text { De } \\
500,01 \text { a } \\
655,19 \\
\text { Euros }\end{array}$ & $\begin{array}{c}\text { De } \\
655,20 \\
\text { a } 700 \\
\text { Euros }\end{array}$ & $\begin{array}{c}\text { De } \\
700,01 \text { a } \\
1100 \\
\text { Euros }\end{array}$ & $\begin{array}{c}\text { De } \\
1100,01 \\
\text { a } 1500 \\
\text { Euros }\end{array}$ & $\begin{array}{c}\text { De } \\
1500,01 \\
\text { a } 1800 \\
\text { Euros }\end{array}$ & $\begin{array}{c}\text { De } \\
1800,01 \\
\text { a } 2000 \\
\text { Euros }\end{array}$ & $\begin{array}{c}\text { De } \\
2000,01 \text { a } \\
2567,29 \\
\text { Euros }\end{array}$ & $\begin{array}{c}\text { Más } \\
\text { de } \\
2567,29\end{array}$ \\
\hline $\begin{array}{l}\text { Jubilación } \\
\left(\mathrm{N}^{\circ}\right)\end{array}$ & 88975 & 755196 & 1404738 & 135035 & 1340632 & 756205 & 382478 & 197540 & 647260 & 23894 \\
\hline $\begin{array}{l}\text { Viudedad } \\
\left(\mathbf{N}^{\circ}\right)\end{array}$ & 45354 & 700307 & 858231 & 86175 & 476778 & 173587 & 16973 & 565 & 636 & 61 \\
\hline $\begin{array}{l}\text { Jubilación } \\
(\%)\end{array}$ & 1,55 & 13,18 & 24,51 & 2,36 & 23,39 & 13,19 & 6,67 & 3,45 & 11,29 & 0,42 \\
\hline $\begin{array}{l}\text { Viudedad } \\
(\%)\end{array}$ & 1,92 & 29,69 & 36,39 & 3,65 & 20,21 & 7,36 & 0,72 & 0,02 & 0,03 & 0,00 \\
\hline
\end{tabular}

${ }^{36}$ Las tablas 14 y 15 han sido elaboradas a partir de la base de datos del INE.

B ANUARI DEL CONFLICTE SOCIAL 2017

DOI. 10.1344/ACS2018.7.6 


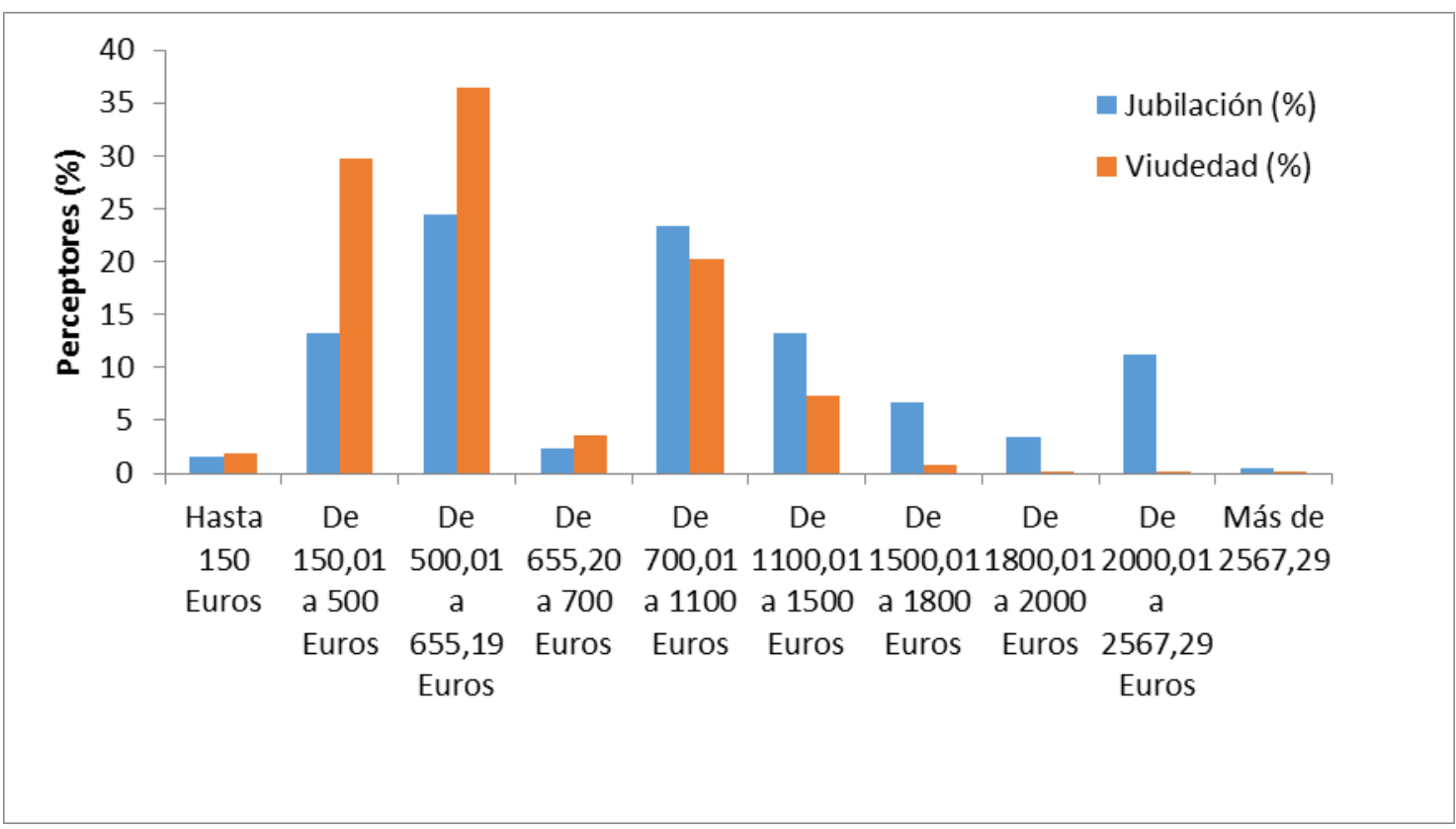

Gráfico 21. Perceptores de pensiones de jubilación y viudedad en $2016(\%)^{37}$

Si nos fijamos en el gráfico 22, comprobaremos que el 39,23\% de los jubilados/as cobraba pensiones de cuantía inferior al Salario Mínimo Interprofesional (SMI) de 2016 ${ }^{38}$. En el caso de las pensiones de viudedad, más de dos tercios de los beneficiarios/as recibían pensiones inferiores al SMI y algo menos de un tercio (31,23\%) recibía una pensión cuyo importe oscilaba entre 1 y 2,3 veces el SMI. Por lo tanto, el porcentaje de viudos/as con retribuciones superiores a los 1500 euros mensuales es despreciable en términos estadísticos.

${ }^{37}$ Los gráficos 21 y 22 han sido elaborados a partir de la base de datos del INE. 38 655,20€/mes. 


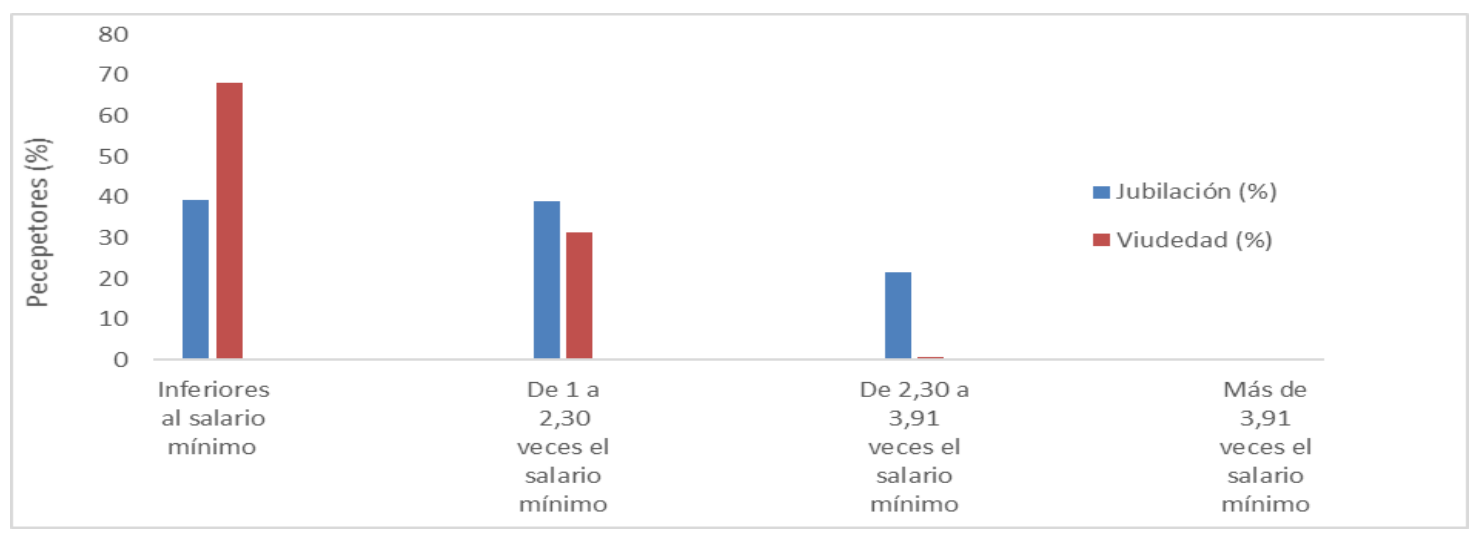

Gráfico 22. Perceptores de pensiones de jubilación y viudedad en relación al salario mínimo (\%)

Llegados a este punto, podemos empezar a extraer algunas conclusiones. En primer lugar, existe una brecha importante entre pensionistas en función del tipo de pensión que reciben, puesto que la mayor parte de viudos/as percibe retribuciones inferiores al Salario Mínimo Interprofesional. En segundo lugar, existe una importante desigualdad retributiva dentro de los pensionistas que reciben una asignación por jubilación. En 2016, el 39,23\% de ellos recibía pensiones de importe inferior al salario mínimo interprofesional y el 64,98\% percibía retribuciones inferiores a los 1100 euros mensuales. Mientras tanto, había un $11,21 \%$ de los pensionistas que ingresaba la pensión máxima (2567,29 euros mensuales). En definitiva, aunque la pensión media haya aumentado de forma sostenida y su importe sea relativamente elevado, no debemos olvidar que existen muchos pensionistas de muy bajos ingresos. Y, en tercer lugar y último lugar, el número de pensionistas con retribuciones entre los 2000,1 y los 2567,29 es singularmente alto. Haciendo un cálculo estimado del gasto efectuado, observamos que más del 25\% del gasto total se realiza en el 
pago de pensiones de más de 2000 euros mensuales. Este dato concuerda con la información revelada por el gráfico 20, según el cual, en España, el quintil superior de la población recibe mayor porcentaje del gato público en transferencias que el quintil inferior.

Tabla 15. Gasto efectuado por sector calculado a partir del promedio de su límite superior y su límite inferior $(\%)^{39}$

\begin{tabular}{|c|c|c|c|c|c|c|c|c|}
\hline & $\begin{array}{c}\text { De } \\
150,01 \text { a } \\
500 \\
\text { Euros }\end{array}$ & $\begin{array}{c}\text { De } \\
500,01 \text { a } \\
655,19 \\
\text { Euros }\end{array}$ & $\begin{array}{c}\text { De } \\
655,20 \\
\text { a } 700 \\
\text { Euros }\end{array}$ & $\begin{array}{c}\text { De } \\
700,01 \text { a } \\
1100 \\
\text { Euros }\end{array}$ & $\begin{array}{c}\text { De } \\
1100,01 \text { a } \\
1500 \\
\text { Euros }\end{array}$ & $\begin{array}{c}\text { De } \\
1500,01 \\
\text { a } 1800 \\
\text { Euros }\end{array}$ & $\begin{array}{c}\text { De } \\
1800,01 \text { a } \\
2000 \\
\text { Euros }\end{array}$ & $\begin{array}{c}\text { De } \\
2000,01 \text { a } \\
2567,29 \\
\text { Euros }\end{array}$ \\
\hline & 325,005 & 577,6 & 677,6 & 900,005 & 1300,005 & 1650 & 1790 & 2283,6 \\
\hline $\begin{array}{l}\text { Jubilación } \\
(\%) \\
\text { Viudedad } \\
(\%)\end{array}$ & 4,23 & 13,99 & 1,58 & 20,80 & 16,95 & 10,88 & 6,10 & 25,48 \\
\hline
\end{tabular}

39 Si hacemos un promedio entre el mínimo y el máximo de cada segmento excluyendo los sectores de menos de 150 y más de 2283,6 (porque son imposibles de promediar) y lo multiplicamos por el número de perceptores (único método. El INE no ofrece datos desagregados), obtenemos el gasto realizado en cada segmento. La tabla muestra el resultado de esta estimación.

B ANUARI DEL CONFLICTE SOCIAL 2017

DOI. 10.1344/ACS2018.7.6 


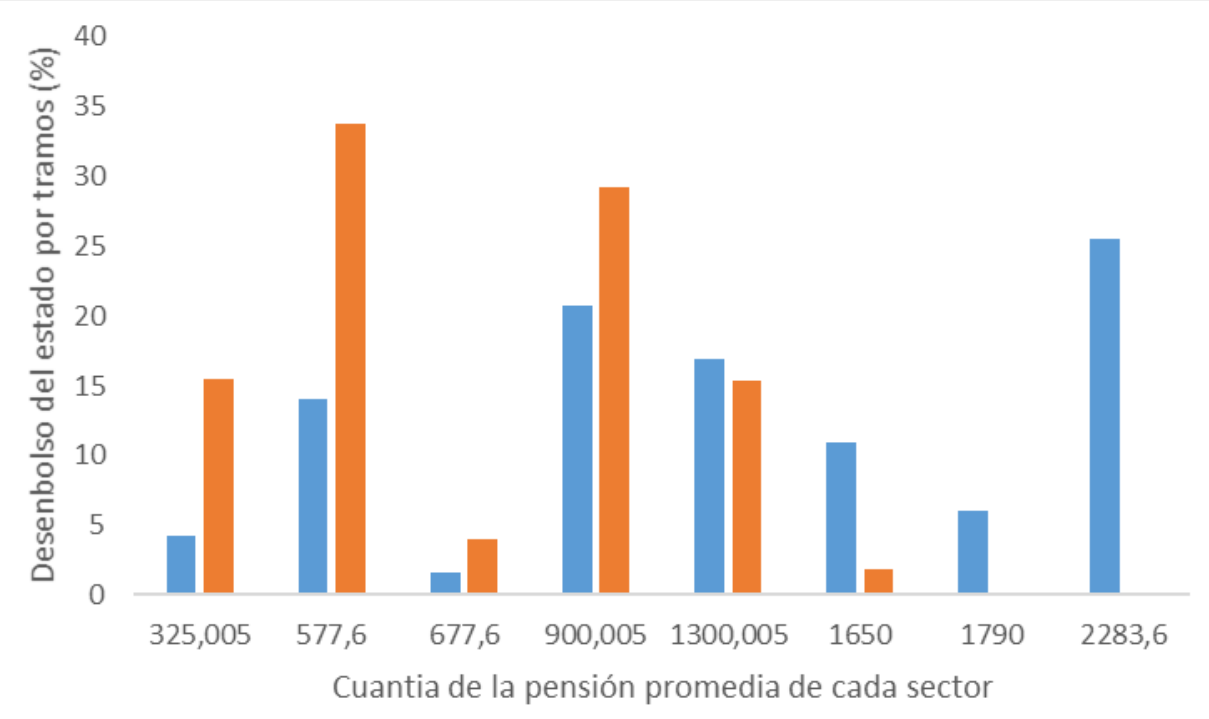

Ilustración 23.Gasto efectuado por sector calculado a partir del promedio de su límites inferior y superior (\%)

\section{La lucha por las pensiones dignas}

A pesar del éxito relativo del sistema de pensiones actual, en estos últimos años, se han aprobado varias reformas del sistema de pensiones cuyo supuesto objetivo era garantizar su sostenibilidad. En el año 2011, el ejecutivo del entonces presidente José Luis Rodríguez Zapatero promovió una ley llamada "Ley de actualización, adecuación y modernización del sistema de Seguridad Social". Dicha disposición legal nacía del acuerdo entre dicho gobierno y las principales organizaciones sindicales y patronales del país y fue apoyada por el Partido Socialista Obrero Español (PSOE) y Convergencia i Unió (CiU). Las dos cuestiones centrales de esta reforma fueron la subida 
progresiva de la edad mínima de jubilación a los 67 años y la ampliación a 25 años del periodo para el cómputo ${ }^{40}$.

En noviembre de 2013, el gobierno del Partido Popular aprobó una segunda reforma del sistema público de pensiones ${ }^{41}$ que establecía las pensiones se revalorizarían entre el 0,25 y $0,50 \%$ por encima del IPC en los años en que la Seguridad Social no tuviese déficit. Sin embargo, cuando la Seguridad Social incurriese en déficit, las pensiones sólo se revalorizarían un $0,25 \%$, sin tener en cuenta el incremento de precios. En definitiva, la reforma abría la puerta a la desindexación eventual de las pensiones con el IPC. Por otra parte, establecía la entrada en vigor del llamado "factor de sostenibilidad" que ajustará las pensiones a la evolución de la esperanza de vida a partir de 2019. Puesto que se prevé un incremento en la esperanza de vida, la instauración del llamado factor de sostenibilidad supondrá, en principio, una disminución progresiva de las pensiones.

Ante esta situación, ha surgido un movimiento que reivindica el fin del factor de sostenibilidad, la revalorización de las pensiones, la derogación del de la Ley de actualización de las pensiones (2011) y la constitucionalización del derecho a la vejez digna como un derecho fundamental, con el mismo nivel de protección jurídica que los derechos recogidos en la sección primera del título segundo de la Constitución. Las movilizaciones se han organizado desde dos espacios distintos: la Mesa por el Blindaje de las Pensiones ${ }^{42}$ y la Coordinadora Estatal por la Defensa del Sistema Público de Pensiones. Este segundo agrupa decenas de plataformas de ámbito local y regional denominadas "mareas pensionistas". La presión

40 https://elpais.com/economia/2011/07/21/actualidad/1311233574_850215.html ${ }^{41}$ https://www.infolibre.es/noticias/economia/2013/11/20/el_aprueba_solitario_r eforma_las_pensiones_entre_acusaciones_burla_provocacion_10015_1011.html 42 http://www.merp.es 
ejercida por los pensionistas y la aritmética parlamentaria obligaron al Grupo Parlamentario Popular a introducir una enmienda en los presupuestos que incrementase las pensiones un 1,6\% en 2018 y según el IPC en 201943.

En los próximos años, la movilización social de los pensionistas será fundamental. En primer lugar, según todos los barómetros del CIS, los mayores de 65 años presentan tasas de abstención muy bajas. Por eso mismo, pueden ejercer una presión enorme sobre el sistema político español. En segundo lugar y último lugar, como bien denuncian algunas organizaciones sociales ${ }^{44}$, los pensionistas han tenido un papel fundamental como sustentadores del gasto familiar de sus hijos y nietos. Por lo tanto, una pérdida del poder adquisitivo de los pensionistas podría suponer una fuerte crisis social de gran envergadura.

\section{Conclusiones}

España es uno de los países más desiguales de la Unión Europea. Además, entre los años 2007 y 2016, la desigualdad interna de nuestro país medida en términos de Gini aumentó de forma paulatina y casi ininterrumpida. Sin embargo, en el conjunto de la Unión Europea a 27 (UE-27), la desigualdad social se redujo en dos décimas. Por este motivo, podemos concluir que se ha producido una divergencia entre España y el conjunto de la Unión en términos de desigualdad.

Por otra parte, en términos de PIB per cápita, España presenta un nivel de desarrollo económico intermedio y se sitúa muy lejos de los

${ }^{43}$ http://www.lavanguardia.com/economia/20180425/442993984548/pnv-
acuerdo-pensiones-revalorizacion-ipc.html

${ }^{44}$ https://www.theeconomyjournal.com/texto-diario/mostrar/592003/abuelosrescate-familia 
países europeos menos desarrollados. En otras palabras, España tiene un nivel de desigualdad impropio de su nivel de desarrollo y, a su vez, es el país más desarrollado entre los más desiguales de la Unión Europea. Este nivel de desigualdad anormalmente alto no se debe a un gasto social insuficiente, puesto que el gasto en transferencias realizado por las administraciones españolas es moderadamente elevado. Tal y como demuestra el escaso impacto de las transferencias sobre el índice de Gini, el origen de este extraño fenómeno es más bien la ineficacia del gasto público.

En cuanto a la pobreza relativa, el porcentaje de españoles que la padecen ha crecido de forma constante y casi ininterrumpida. En términos comparados, se encuentra entre los países europeos con mayores tasas de pobreza. Al inicio de periodo estudiado, era el sexto país europeo con mayor índice de pobreza relativa y, al final de este, había alanzado el tercer puesto de la lista.

Por otra parte, como el resto de países del sur de Europa, España registra simultáneamente niveles altos de pobreza relativa y gasto social. Por lo tanto, podemos concluir que la acción del estado tampoco logra reducir la pobreza de forma eficaz. Sin embargo, si analizamos el nivel de pobreza antes y después de transferencias por grupos de edad, comprobamos que, en nuestro país, el gasto en pensiones reduce notoriamente las probabilidades de vivir bajo el umbral de la pobreza. Sin embargo, el gasto público se muestra particularmente ineficaz a la hora de atenuar la pobreza entre las personas de menor edad.

Como se ha demostrado en este artículo, los altos niveles de pobreza infantil y juvenil son consecuencia de un déficit de inversión en políticas de apoyo a las familias en edad de trabajar. A mi entender, este es el motivo por cual el gasto social no es capaz de combatir la pobreza y las desigualdades de forma adecuada. En efecto, si hacemos un análisis comparado, se observa una relación inversamente 
proporcional entre el gasto en familia y los niveles de pobreza y desigualdad. Dicho de otro modo, los países más igualitarios desarrollan una mayor inversión en políticas de apoyo a las familias. Este hecho ocurre por dos motivos. En primer lugar, la mayor parte de perceptores del gasto en familia son los sectores más empobrecidos de la sociedad. En segundo lugar, este tipo de transferencias se financian a través de impuestos progresivos y sus principales sustentadores son los contribuyentes de clase media y alta. En cambio, cuando el grueso del gasto social se financia a través de cotizaciones, este resulta menos progresivo, puesto que los sectores menos favorecidos reciben un parte proporcionalmente menor.

En cuanto a las causas del incremento de la pobreza en estos últimos años, este artículo ha mostrado que se pueden resumir en dos: la persistencia del desempleo y el ajuste a la baja de los salarios. Como se ha podido comprobar observando la participación de los salarios en el PIB, el precio de la fuerza de trabajo se ha visto muy marcado por los cambios en la legislación que regula las relaciones laborales. Por otra parte, si analizamos la participación de cada quintil en la riqueza nacional, concluimos que ha habido una transferencia de rentas de los sectores más empobrecidos de la población hacia los dos más pudientes. En lo que ataque a los grupos sociales intermedios (tercer quintil), estos han mantenido intacta su posición en relación al resto de quintiles.

Para terminar, en cuanto a la percepción social de las desigualdades, podemos extraer varias conclusiones. En primer lugar, si bien las desigualdades sociales son consideradas como un problema por buena parte de la sociedad española, la mayoría de españoles piensa que el rol principal del estado no debe ser reducir la brecha entre ricos y pobres, sino promover la igualdad de oportunidades y garantizar un nivel de bienestar mínimo para todos los ciudadanos. En segundo lugar, teniendo en cuenta la importancia atribuida al crecimiento económico, 
podemos deducir que buena parte de los españoles confían en el progreso económico y en el empleo como medios para mejorar la inserción social de los sectores desfavorecidos. En tercer y último lugar, la mayor parte de españoles es proclive a aumentar los impuestos para mejorar los niveles de protección social, aunque el porcentaje de ciudadanos que prefieren reducir la carga fiscal a costa de mejores niveles de protección social es prácticamente igual. En definitiva, si bien la desigualdad y las cuestiones de índole social son muy importantes en la opinión pública de nuestro país, la mayor parte de ciudadanos no parecen identificar una solución en el gasto social, aunque se pueda constatar empíricamente que las sociedades más justas e igualitarias son aquellas que efectúan un gran gasto social en apoyo a las familias en edad de trabajar.

\section{Bibliografía}

CENTRO DE INVESTIGACIONES SOCIOLÓGICAS (2011).

"Barómetro septiembre", 03/06/2018, http://www.cis.es/cis/opencm/ES/1 encuestas/estudios/ver.jsp?e $\underline{\text { studio }}=11844$

DIARIO CRÍTICO (2018). "El Banco de España mejora las previsiones económicas y apunta a un crecimiento del $2,7 \%$ en 2018 ", 03/06/2018, https://www.diariocritico.com/banco-de-espanamejora-las-previsiones-economicas-2018.

EL PAIS (2011). "El Congreso aprueba hoy la reforma de las pensiones que retrasa la jubilación hasta los 67 años", 06/06/2018, https://elpais.com/economia/2011/07/21/actualidad/1311233574 850215.html

EUROPAPRESS (2018). "El BCE revisa al alza su previsión de crecimiento para 2018 y advierte de la amenaza del proteccionismo", 03/06/2018 http://www.europapress.es/economia/macroeconomia00338/noticia-bce-revisa-alza-prevision-crecimiento-2018-advierteamenaza-proteccionismo-20180308152035.html 
EUROSTAT (2018). "Datebase”, 03/06/2018, http://ec.europa.eu/eurostat/help/first-visit/database

INSTITUTO NACIONAL DE ESTADÍSTICA (2018). "Base de datos sobre mercado laboral", 03/06/2018, http://www.ine.es/dyngs/INEbase/es/categoria.htm?c=Estadistica P\&cid $=1254735976595$

LA VANGUARDIA (2018). "El PNV salva las cuentas de Rajoy a cambio de subir las pensiones", 06/06/2018, http://www.lavanguardia.com/economia/20180425/442993984548 /pnv-acuerdo-pensiones-revalorizacion-ipc.html

MARS, Amanda (2018). "El FMI eleva el crecimiento de España al 2,8\% para 2018 pero alerta de sus desequilibrios", 03/06/2018, https://elpais.com/economia/2018/04/17/actualidad/1523923082 420998.html

MINISTERIO DE EMPLEO Y SEGURIDAD SOCIAL (2017).

"Pensiones Contributivas del Sistema de la Seguridad Social", 06/06/2018,http://www.empleo.gob.es/es/estadisticas/anuarios/20 16/PEN/PEN.pdf

OCDE (2014). "Social Expenditure Update", 03/06/2018,https://www.oecd.org/els/soc/OECD2014SocialExpenditure Update19Nov Rev.pdf

THE ECONOMY JOURNAL (2018). "Los abuelos al rescate de la familia", 06/06/2018, https://www.theeconomyjournal.com/textodiario/mostrar/592003/abuelos-rescate-familia 